\begin{tabular}{|l|l|l|l|l|l|}
\hline MUNIBE Antropologia-Arkeologia & $n^{\circ} 65$ & $215-237$ & DONOSTIA & 2014 & ISSN 1132-2217 • eISSN 2172-4555 \\
\hline
\end{tabular}

\title{
Estructuras de fondo rehundido altomedievales en la Península Ibérica
}

\author{
Early middle age sunken featured buildings in the Iberian Peninsula
}

KEY WORDS: Early Middle Age household architecture; Household archaeology; Village archaeology; Early Middle Ages; Peasant societies. PALABRAS CLAVES: Arquitectura doméstica altomedieval; Arqueología de la arquitectura; Arqueología de las aldeas; Alta Edad Media; Sociedades campesinas.

GAKO-HITZAK: Goi Erdi Aroko etxe-arkitektura; Arkitekturaren arkeologia; Herrixken arkeologia; Goi Erdi Aroa; Nekazarien gizarteak.

Carlos TEJERIZO GARCíA(1)

\begin{abstract}
The presence of sunken featured buildings in early medieval contexts is well documented throughout Europe and has been the object of many studies. The urban expansion and further development of commercial archaeology in the Iberian Peninsula has allowed for the recording of a very significant amount of these structures, as almost five hundred samples have been excavated during the last twenty five years. Thanks to this we can now compare the Iberian case to the processes documented elsewhere in Europe. However, the data has not been properly systematized and analysed, something which has dragged the detection and documentation of similar structures and has also given place to interpretative excesses. The main aim of this paper is to carry out a comprehensive analysis of this type of structure building on all the evidence that is currently available, as well as to propose and interpretation of its appearance, and eventual disappearance, in the context of the Early Middle Ages in the Iberian Peninsula. It is divided in three parts. In the first one, some conceptual considerations regarding a critical review of the different names used for this type of structure will be made, proposing the use of the expression "sunken featured building". The taphonomical processes that might affect this type of structures, sometimes significantly distorting them, will also be considered. In the second part an analysis of all the available empirical evidence is made. For this, three complementary criteria have been chosen: typological, structural and spatial. The analysis demonstrates that the development of this type domestic architecture in the Iberian Peninsula during Early Middle Ages was very diverse. The evidence shows a very marked typological and structural variability in the chaines opératoires that were followed in their construction. At the same time, it shows that there existed common patterns in their spatial location within the sites. In order to discern the peculiar characteristics of the Iberian case study, some comparisons in a European scale, mainly with study cases from England, France, Italy and Iceland, will be made. Finally, a discussion on the historical context of the appearance and disappearance of this structure will be made, proposing an interpretation related with the gradual development of a peasant mode of production materialized after the disarticulation of roman imperial economy in the fifth century. Some reflections on the interpretations that link the appearance of this type of buildings to the arrival of foreign ethnic groups in the sixth century will also be made.
\end{abstract}

\section{RESUMEN}

La presencia de estructuras de fondo rehundido en contextos arqueológicos altomedievales está ampliamente documentada en toda Europa y cuenta con una dilatada historiografía. En la Península Ibérica, asociado a la expansión urbanística, se ha podido detectar un conjunto muy significativo de estas estructuras. Sin embargo, la falta de sistematización y análisis ha llevado a algunos problemas en su detección y documentación, así como a excesos conceptuales y de interpretación. En este trabajo se realiza una recopilación analítica de las evidencias de estructuras de fondo rehundido de época altomedieval presentes en la Península Ibérica mostrando su alta complejidad y diversidad. Basado en un análisis de la evidencia disponible, y frente a las tesis etnicistas que las vinculan a la llegada de grupos alóctonos, se propone una interpretación relacionada con el desarrollo de un modo de producción campesino tras la desarticulación de la economía imperial romana.

\section{LABURPENA}

Goi Erdi Aroko testuinguru arkeologikoetan, hondo berrondoratuko egituren presentzia oso dokumentatuta dago Europa osoan eta historiografia zabala du. Iberiar penintsulan, hirigintzaren hedapenari lotuta, egitura horien oso multzo garrantzitsua detektatu ahal izan da. Hala ere, sistematizazioan eta analisietan izandako gabeziak direla-eta, hainbat arazo sortu dira egitura horiek detektatzeko eta dokumentatzeko. Gehiegikeria kontzeptualak eta interpretazioko gehiegikeriak ere egin izan dira. Lan honetan, Iberiar penintsulan presentzia duten Goi Erdi Aroko egituren ebidentzien bilketa analitikoa egin dugu, eta dituen konplexutasuna eta dibertsitatea erakutsi nahi izan ditugu. Eskuragarri dagoen ebidentziaren analisian oinarrituta eta aipatutako egitura horiek talde aloktonoen etorrerarekin lotzen dituzten tesi etnizisten aurka, erromatarren inperioko ekonomia desegin ondoren etorritako nekazaritzako ekoizpen moduaren garapenari lotutako interpretazio bat proposatuko dugu.

(1) Becario FPU. Departamento de Geografía, Prehistoria y Arqueología. Universidad del País Vasco/Euskal Herriko Unibertsitatea. C/Fco Tomás y Valiente, s/n, 01006, Vitoria-Gasteiz. Álava. carlosteje@gmail.com. 


\section{1.- INTRODUCCIÓN}

Una de las puntas de lanza en la renovación de la arqueología medieval en la Península Ibérica ha sido el desarrollo de una arqueología de las aldeas que ha puesto de relieve la importancia del estudio del campesinado como parte esencial en la constitución de las sociedades medievales. Los avances en la investigación están logrando, como bien afirma $\mathrm{H}$. Kirchner, poner el nivel de la arqueología medieval peninsular al de sus homólogas europeas (KIRCHNER, 2010: 244). Una vez pasada la vorágine de la destrucción de patrimonio que contextualizó y estructuró este desarrollo de la arqueología de las aldeas, parece que llega el momento de reflexionar críticamente sobre los datos obtenidos para convertirlos en una masa empírica sobre la que fundamentar marcos interpretativos y narraciones históricas sólidas.

Uno de los símbolos materiales de esta Arqueología de las Aldeas han sido las estructuras de fondo rehundido, que constituyen uno de los testimonios más evidentes de la transición entre el fin de la economía tardoimperial y el poblamiento rural postromano. A pesar de su importancia en el registro material los trabajos de síntesis al respecto son todavía escasos, salvo algunas notables incursiones (ALFARO, 2012; AZKARATE y QUIRÓS CASTILLO, 2001; LÓPEZ QUIROGA, 2006; VIGIL-ESCALERA, 2000) que, sin embargo, no han llegado a evaluar toda la masa empírica disponible1. Estas carencias, sumadas a la pujante arqueología de las aldeas, ha llevado a algunos excesos conceptuales a la hora de identificar y analizar estas estructuras como ya predijeran en su día A. Azkarate y J.A Quirós (AZKARATE y QUIRÓS CASTILLO, 2001: 27)2. No es extraño encontrar informes y estudios arqueológicos en los que se considera un "fondo de cabaña" a cualquier estructura rebajada, sea cual sea su morfotipología, contenido material o relación estratigráfica dentro del contexto arqueológico. Igualmente, la falta de análisis contextual de estas estructuras han generado algunas interpretaciones deterministas, dentro de la órbita de la historia-cultural y las lecturas etnicistas que asocian la aparición de las estructuras de fondo rehundido y su difusión a las "invasiones bárbaras".

El presente trabajo pretende no sólo ser una puesta al día del conocimiento sobre estas estructuras, sino también una reflexión sobre su lugar dentro de las sociedades altomedievales en el contexto europeo. Así, se enfatizará la enorme variabilidad constructiva reflejo de la enorme y estimulante diversidad cultural de las sociedades altomedievales, pero también la presencia de patrones comunes que nos permiten insertar la estructura dentro de las dinámicas sociales que les dieron forma.

\section{2.- CONSIDERACIONES PREVIAS}

\subsection{Algunos apuntes sobre terminología}

Las estructuras que son el objeto de este trabajo han sido denominadas de diversas maneras. En la literatura en lengua castellana encontramos términos como "fondos de cabaña", "cabañas de suelo rehundido", "cabañas" o la apropiación de términos en otros idiomas como "sunken featured buildings" (abreviado en ocasiones como SFBs) o el término alemán "Grubenhaus" usados de forma indistinta. Este último es el más utilizado en el norte de Europa y también en Inglaterra (WÜSTEHUBE, 1996; TIPPER, 2004). Su traducción literal sería "casa-en-hoyo" (pit-house) y haría referencia a estructuras cuya cota de uso estaría rehundida, cuestión que, como veremos, no es generalizable a todos los casos.

Otro término muy utilizado es el de "cabaña" o "fondo de cabaña", préstamo derivado del fond de cabanne francés, muy extendido a partir de los trabajos realizados en los años 80 (CHAPELOT, 1980; CHAPELOT y FOSSIER, 1980: 116 y ss.). Un concepto que, en lengua castellana, connota ruralidad, pobreza, tosquedad, marginalidad y provisionalidad "que no responden al espíritu de las construcciones altomedievales que constituyeron, en muchas ocasiones, lugares de hábitat permanentes" (AZKARATE y QUIRÓS CASTILLO, 2001: 28). En concreto, la primera acepción de la RAE de la voz "cabaña" hace mención al uso "de materiales pobres, generalmente palos entretejidos con cañas"; definición que no refleja la enorme variedad de formas que adopta lo que comúnmente podemos entender como "cabaña", que puede estar construida perfectamente en materiales pétreos, como los teitos asturianos o las pallozas leonesas, formas tradicionales y paradigmáticas de "cabañas" todavía presentes en el registro actual. En este sentido, cualquier edificio rural de materiales "pobres" (dependiendo, claro está, de lo que se entienda por "pobre") podría ser entendido como una "cabaña".

Formalmente, el término "cabaña" en contextos altomedievales es muy impreciso. Puede hacer referencia tanto a estructuras rehundidas (objeto del presente trabajo) como a estructuras construidas en superficie ya sea con cimentación de piedra o con estructuras de madera (las denominadas post-built buildings en la literatura anglosajona o structures en poteaux en el ámbito francés). Igualmente, el uso del término "cabaña" presupone en parte la funcionalidad final del edificio, sin pasar por su caracterización arqueológica y formal (AZKARATE y QUIRÓS CASTILLO, 2001: 28). Si bien entiendo que muchas de las estructuras fueron "cabañas" en base a la percepción normativa actual más extendida, el uso de este término podría inducir a ciertos apriorismos funcionales y formales en el estudio arqueológico de las sociedades altomedievales.

\footnotetext{
${ }^{1}$ Hay que mencionar, por la importancia en la recogida de datos para este trabajo el volumen de 2006 de Zona Arqueológica dedicado a La investigación arqueológica de la época visigoda en la Comunidad de Madrid, y a la publicación de las actas del Congreso de Arqueología de las Aldeas celebrado en Vitoria en el año 2008, publicadas en 2009 (QUIRÓS CASTILLO, 2009).

2 "Entre nosotros, la indefinición es general, siendo frecuente el recurso a descripciones y denominaciones excesivamente confusas. Términos como "manchas de tierra oscura", "basureros", "agujeros de poste", "silos", "cabañas", "fondos de cabaña", etc. se utilizan indistintamente, sin explicitar casi nunca ni tipologías ni funcionalidades".
} 
El término anglosajón "sunken featured building" fue utilizado por primera vez por P. Rahtz para evitar problemas similares y como alternativa a la propuesta de E.T. Leeds de asociar estas estructuras con viviendas "miserables" (TIPPER, 2004: 3). Este término hace referencia directa a la que supone la característica diferenciadora de este tipo de estructura frente a otras arquitecturas domésticas, que es su fondo rehundido y que la particulariza con respecto al resto de la arquitectura doméstica presente en contextos altomedievales. En este sentido, y siguiendo la propuesta de Rahtz y de S. West (WEST, 1986), el término que servirá para caracterizar estas estructuras a lo largo del trabajo será el de estructura de fondo rehundido (se utilizará también el acrónimo EFR en adelante).

Podemos definir preliminarmente las estructuras de fondo rehundido altomedievales, con el fin de delimitar el objeto de estudio, como una estructura doméstica cuyo elemento estructural más destacado, en términos de registro arqueológico, es una fosa excavada en el terreno natural, más o menos regularizada y de fondo allanado y cuya morfología se caracteriza por ser más extensa que profunda y más o menos regular en torno a formatos ovalados o cuadrangulares/rectangulares. Sobre este hoyo se levantaría la superestructura edilicia, generalmente de materiales perecederos de tierra y madera, y a la que se le pueden añadir o no distintos elementos estructurales internos o de mobiliario, domésticos (hogares, hornos, etc.) y/o simbólicos (enterramientos infantiles, depósitos fundacionales, etc.)

Esta conceptualización de las EFR nos permite diferenciarlas a priori de otras estructuras similares, como las estructuras tipo silos, definidas como estructuras generalmente "de planta circular con diámetros comprendidos entre los 70/80 y los 200/300 cm. cuyo perfil sea compatible con el de un contenedor de boca estrecha" (VIGIL-ESCALERA, 2013: 128-129), es decir, más profundas que extensas, y con un suelo no necesariamente plano. También serían diferentes de las estructuras tipo cubetas, de formato irregular tanto en su morfología como en la conformación del fondo de la estructura e, igualmente, de otras estructuras con otras morfologías diferenciadas, como lagares excavados en el suelo, lagunas naturales, etc.

\subsection{Tafonomía y procesos postdeposicionales}

Las particulares características de las estructuras negativas hacen necesarias algunas precauciones en relación a la formación del registro. Las cuestiones tafonómicas son especialmente importantes debido a las características concretas de su cadena operativa y al hecho de que en casi todos los casos el objeto de análisis arqueológico es la parte rehundida frente a la aérea, que sólo podemos re-construir en el presente (VIGIL-ESCALERA, 2000: 227). De la estructura inicial compuesta por la fosa, el alzado, la techumbre, los elementos muebles y las estructuras adosadas solo nos quedan las estructuras negativas excavadas en el nivel geológico, que se ven muy afectadas por los procesos postdeposicionales que hayan tenido lugar, dejando únicamente la huella final de lo que en su día fue la estructura completa. Este aspecto es muy claro en algunos ejemplos en los que documentan agujeros de poste alrededor de la fosa, que nos advierte de que la fosa es únicamente una parte de una estructura mayor. Estos procesos son especialmente intensos en espacios agrarios actuales, como ocurre en espacios como la Meseta Central (figura 1)

J. Tipper calcula que, lo que observamos a la hora de excavar es, de media, unos 40-50 cm. más bajo del nivel inicial, aunque la casuística concreta de cada yacimiento, e incluso dentro de cada yacimiento, es mucho más compleja (TEJERIZO GARCÍA, 2013b). A través de estudios de arqueología experimental sobre estructuras de fondo rehundido construidas para registrar su colapso a lo largo de siete años se pudo observar que la variación de tamaño era muy significativa, aumentando la estructura casi medio metro de largo y cerca de $2 \mathrm{~m}^{2}$ de superficie (TIPPER, 2004: 65, 104 y ss). Del mismo modo, los asentamientos rurales excavados en la Península Ibérica, y sobre todo en zonas como la Meseta Central, se han visto tremendamente afectados por los procesos de mecanización y concentración parcelaria a partir de los años 80 , lo que ha conllevado una importante pérdida del registro material, de cerca de $1 \mathrm{~m}$. en algunos casos. El desbroce superficial con ciertas máquinas pesadas también distorsiona de forma significativa estas estructuras y están en el origen de muchas ausencias materiales en el contexto peninsular.

Existen dos procesos básicos de amortización de estas estructuras que serán determinantes no solo para su configuración como registro arqueológico sino para la interpretación estratigráfica e histórica del sitio. El primero sería el uso como lugares de deposición de los restos de producción y consumo por parte de la comunidad, esto es, como basureros. Esta forma de amortización determina enormemente la formación del depósito arqueológico por su condición mayoritaria de depósitos secundarios o terciarios (QUIRÓS CASTILLO, 2012: 65) y pueden llegar a distorsionar de forma determinante aspectos como la cronología o funcionalidad debido a los procesos de abandono (CAMERON, 1991). Como consecuencia de estos, la potencial "residualidad" de los depósitos cerámicos que en ella se encuentran es un aspecto a valorar, no sólo en estas estructuras, sino en el conjunto de la arquitectura doméstica negativa presente en los yacimientos rurales altomedieva-

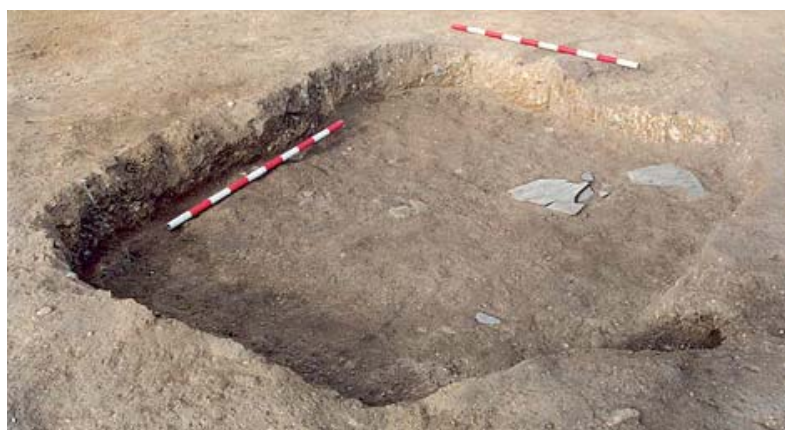

Fig. 1. EFR de La Mata del Palomar. A la derecha se puede observar la huella de un arado (STRATO, 2002). / SFB from La Mata del Palomar. On the right a plough trace can be seen. 
les. Una lectura acrítica de los procesos de formación puede llevar a interpretaciones cronológicas erróneas y nos advierte de la necesidad de un análisis estratigráfico minucioso de los materiales del relleno de estas estructuras a contrastar con las dataciones absolutas obtenidas.

La segunda manera de amortización es la geológico/natural a través de estratos que se han posicionado progresivamente (a través del viento, animales, etc.), más lenta que la anterior aunque de relativa velocidad de colmatación. La ausencia de materiales en el relleno de estas estructuras podría ser un indicador de este proceso y, por lo tanto, de un abandono no solo de la estructura, sino quizá también de partes sustanciales de yacimiento. En ciertos casos, la presencia de ciertos líquenes en el registro polínico muestra una exposición de la estructura tras su abandono dilatada en el tiempo, como ocurre en El Pelambre (LÓPEZ SÁEZ, et al., 2009). En cualquier caso, según Tipper, "The archaeological evidence and experimental research indicates that most Grubenhäuser were rapidly infilled after the building had been abandoned" (TIPPER, 2004), lo que nos estaría indicando que el principal modo de abandono es el primero.

Junto con los procesos tafonómicos y postdeposicionales, el otro elemento fundamental a tener en cuenta es la geología del terreno dado el carácter de estructura negativa de las EFR. Evidentemente, las características geológicas del lugar donde se pretenden realizar estas estructuras será determinante a la hora de configurar su morfología, los procesos postdeposicionales e, incluso, su existencia o ausencia. J. Tipper es claro en este aspecto cuando sugiere que "the construction of Grubenhäuser, however, appears to have been a pragmatic response to the immediate environment; the underlying geology played a prominent and often determining role in the construction of structural types... Put simply, the effort taken to dig a large pit into chalk bedrock [caliza] presumably outweighted the functional benefits of the structure" (TIPPER, 2004: 25). Ya en otro trabajo sugería que la ausencia de estas estructuras en algunas de las zonas de la cuenca del Duero, en concreto la zona del suroeste, de amplia formación granítica, se debía a la conformación geológica del terreno, que dificultaba la construcción de estructuras negativas. Cuestiones geológicas, que, a su vez, tendrán implicaciones socioeconómicas, con una diferente organización de las unidades domésticas en torno a los espacios aldeanos (TEJERIZO GARCÍA, 2012: 24; TIPPER, 2004).

\section{3.- CARACTERIZACIÓN GENERAL DE LAS ES- TRUCTURAS DE FONDO REHUNDIDO EN LA PENÍNSULA IBÉRICA}

Teniendo en cuenta los problemas para la recopilación de información sobre las estructuras de fondo rehundido ${ }^{3}$, se ha podido reconocer la existencia de, al menos, 530 (aunque el número real es, con seguridad, muy superior) en 82 yacimientos de la Península Ibérica ${ }^{4}$ concentrados significativamente en las actuales comunidades autónomas de Castilla y León (cerca de 116 fondos de cabaña), Cataluña (67 estructuras), Madrid (332 estructuras) y País Vasco (15 estructuras) si bien se han detectado posibles EFRs en otros entornos como Estepona, Málaga (PÉREZ RAMOS, 2008) (Figura 2 y tabla I) ${ }^{5}$. Se trata de un número sorprendentemente alto pero nada inesperado dada la alta frecuencia de aparición de estas estructuras en entornos rurales altomedievales en contextos europeos. Esta distribución tan desigual está relacionada no tanto con factores históricos sino con cuestiones administrativas y económicas en relación al desarrollo del sector de la construcción y de la arqueología comercial en cada región.

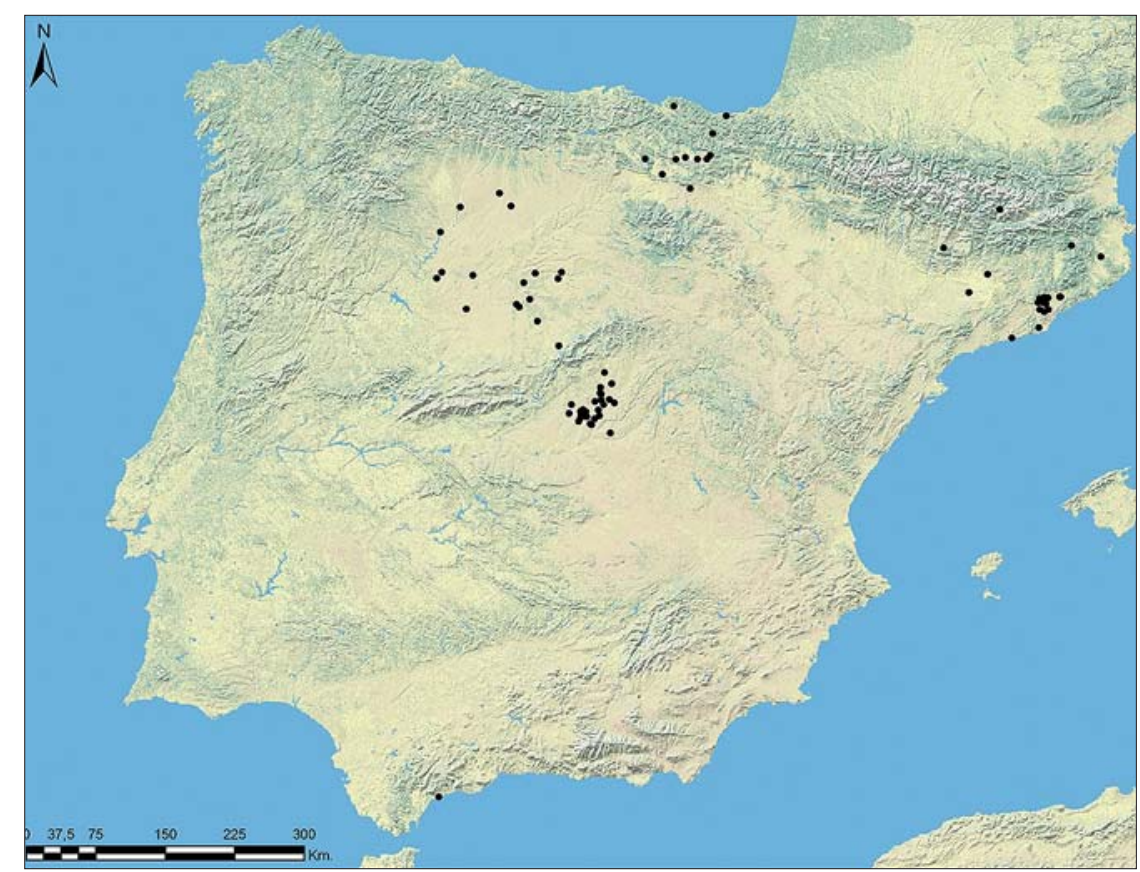

Fig. 2. Distribución de las estructuras de fondo rehundido en contextos medievales en la Península lbérica. / Distribution of sunken featured buildings in early medieval sites in the Iberian Peninsula.

\footnotetext{
${ }^{3}$ Sobre todo, la falta de datos y referencias parciales en los informes de excavación y artículos publicados.

${ }^{4}$ Excluyendo Portugal, de la que no se ha podido recoger información sobre la existencia de fondos de cabaña publicados. Esto no excluye su existencia efectiva, al menos en el centro y norte portugués.
}

${ }^{5}$ Como ejemplo comparativo, el estudio llevado a cabo por Alfonso Vigil-Escalera en 2000 comprendía 70 ejemplares de 2 yacimientos 


\begin{tabular}{|c|c|}
\hline YACIMIENTO & LOCALIZACIÓN \\
\hline Cárcava de la Peladera & Hontoria, Segovia \\
\hline La Mata del Palomar & Nieva, Segovia \\
\hline Carratejera & Navalmanzano, Segovia \\
\hline El Cementerio & Langayo, Valladolid \\
\hline Ladera de los Prados & Aguasal, Valladolid \\
\hline Las Lagunillas & Aldeamayor de San Martín, Valladolid \\
\hline Revenga & Miranda de Ebro, Burgos \\
\hline El Pelambre & Villaornate, León \\
\hline Navamboal & Íscar, Valladolid \\
\hline Senovilla & Olmedo, Valladolid \\
\hline Peña del Mazo & Pajares, Burgos \\
\hline Las Escorralizas/Camino de Quiñones & Cogollos, Burgos \\
\hline Las Hiruelas & Burganes de Valverde, Zamora \\
\hline Canto Blanco & Calzada de Coto, León \\
\hline El Judío & Monfarracinos, Zamora \\
\hline Los Billares & Zamora \\
\hline Las Lagunillas & Aldeamayor de San Martín, Valladolid \\
\hline El Cañal & Pesquera de Duero, Valladolid \\
\hline Gallegos & Pozo de Urama, Palencia \\
\hline Vega de Duero & Villabáñez, Valladolid \\
\hline Gózquez & San Martín de la Vega, Madrid \\
\hline Loranca & Fuenlabrada, Madrid \\
\hline Plaça Major de Castellar del Vallès & Castellar del Vallès, Barcelona \\
\hline Aiguacuit & Terrassa, Barcelona \\
\hline Can Cabassa & Sant Cugat del Vallès, Barcelona \\
\hline Can Solà del Racó & Matadepera, Vallès \\
\hline Can Palau & Sentmenat, Barcelona \\
\hline Can Gambús-1 & Sabadell, Barcelona \\
\hline Els Mallols & Cerdanyola, Barcelona \\
\hline La Solana & Cubelles, Barcelona \\
\hline La Bastida & Rubí, Barcelona \\
\hline Indiana & Pinto, Madrid \\
\hline Pelícano & Arroyomolinos, Madrid \\
\hline La Huelga/El Malecón & Barajas, Madrid \\
\hline Congosto & Rivas-Vaciamadrid, Madrid \\
\hline La Huelga & Barajas, Madrid \\
\hline Encadenado & Barajas, Madrid \\
\hline La Huesa & Cañizal, Zamora \\
\hline Gasteiz & Vitoria-Gasteiz, Álava \\
\hline Igartubeiti & Ezkio-Itsaso, Gipuzkoa \\
\hline Landetxo Goikoa & Mungia, Vizcaya \\
\hline Alegria-Dulantzi & Álava \\
\hline Prado Viejo & Torrejón de la Calzada, Madrid \\
\hline Las Charcas & Barajas, Madrid \\
\hline Prado de los Galápagos & San Sebastián de los Reyes, Madrid \\
\hline Zarautz Jauregia & Zarautz, Guipúzcoa \\
\hline Laguardia & Álava \\
\hline La Cuadrá & Colmenar de Oreja, Madrid \\
\hline Buzanca 2 & Ciempozuelos, Madrid \\
\hline El Guijo y El Bajo del Cercado & Barajas, Madrid \\
\hline La Recomba & Getafe, Madrid \\
\hline Frontera de Portugal & Barajas, Madrid \\
\hline Monte de la Villa & Villaviciosa de Odón, Madrid \\
\hline Las Dehesillas & Parla, Madrid \\
\hline Fuente de la Mora & Leganés, Madrid \\
\hline La Torrecilla & Perales del río, Madrid \\
\hline Camino de Santiago & Madrid \\
\hline Casas de Bahezuela II & San Fernando de Henares, Madrid \\
\hline
\end{tabular}

\begin{tabular}{|c|c|}
\hline YACIMIENTO & LOCALIZACIÓN \\
\hline Casas de Bahezuela III & San Fernando de Henares, Madrid \\
\hline Valdelayegua & Torres de la Alameda, Madrid \\
\hline Sitges de Torre Bargallona & Cambrils, Tarragona \\
\hline Sant Pelegrí Nord & Biosca, Lérida \\
\hline Ca n'Oriol & Rubí, Barcelona \\
\hline Camp Vernell & Sant Julià de Lòria, Andorra \\
\hline Pla del Serrador & Franqueses del Vallès, Barcelona \\
\hline Ca l'Estrada & Canovelles, Barcelona \\
\hline Can Roqueta & Sabadell \\
\hline Can Guardiola & Viladecans, Barcelona \\
\hline Castellarnau & Sabadell \\
\hline Els Altimiris & Sant Esteve de la Sarga, Lleida \\
\hline L'Aubert & Vall d'en Bas, Gerona \\
\hline Aistra & Zalduondo, Álava \\
\hline Zornoztegi & Salvatierra, Álava \\
\hline Zaballa & Nanclares de Oca, Álava \\
\hline Arroyo Vaquero & Estepona, Málaga \\
\hline Ahijones & Vicálvaro, Madrid \\
\hline Los Cirates & Fresno de Torote, Madrid \\
\hline Valdetorres de Jarama & Madrid \\
\hline Quintano & Mejorada del Campo, Madrid \\
\hline Soto Pajares/Casa de Venezuela & San Martín de la Vega, Madrid \\
\hline El Esparragal & Pinto, Madrid \\
\hline Pla de l'Horta & Sarrià de Ter, Gerona \\
\hline
\end{tabular}

Tabla 1: Listado de yacimientos donde se han documentado las estructuras de fondo rehundido analizadas en el presente trabajo.

Table 1: List of sites with sunken featured buildings analysed in the paper.

\subsection{Características morfotipológicas y morfo- métricas}

El creciente número de EFRs detectado en ámbito europeo ha permitido una amplia sistematización de sus características morfotipológicas (en este sentido los principales trabajos serían CHAPELOT, 1980; DONAT, 1980; FRONZA, 2009; PEYTREMANN, 2003; VIGIL-ESCALERA, 2000, entre otros). El análisis estadístico presentado en la figura $3^{6}$ muestra que la gran mayoría de las EFRs se concentran en torno a una media estimada en 4,5 $\times 2,9^{7}$, que coinciden plenamente con los resultados de J.Tipper (TIPPER, 2004)8 y otros autores (JONES, 1979; MARSHALL y MARSHALL, 1991) para el caso anglosajón o para el caso francés (PEYTREMANN, 2012).

En cuanto a la superficie, aquellas EFRs sobre las que disponemos de mejores datos (172 estructuras) nos ofrece un área media de $11 \mathrm{~m}^{2}{ }^{9}$ con estructuras entre los 4 y los 37 $m^{2}$. Es importante tener en cuenta que este dato no es equi-

\footnotetext{
${ }^{6}$ Se ha realizado sobre 211 EFRs de las que disponemos de los largos y los anchos completos y cuya área es superior a $4 \mathrm{~m}^{2}$.

${ }^{7}$ Teniendo en cuenta que la desviación estándar se encuentra en 2,1 en el largo y de 1,2 en el ancho.

${ }^{8}$ Este análisis se realizó sobre 389 EFRs (195 en el yacimiento de Mucking, 133 en West Herleston y 61 en West Stow).

${ }^{9}$ De este análisis hemos eliminado aquellas estructuras superiores a $40 \mathrm{~m}^{2}$ (3 estructuras) por entender que desvirtuaban el análisis así como por las dudas que ofrecían (vid. infra). La desviación estándar de este cálculo es de $7 \mathrm{~m}^{2}$.
} 


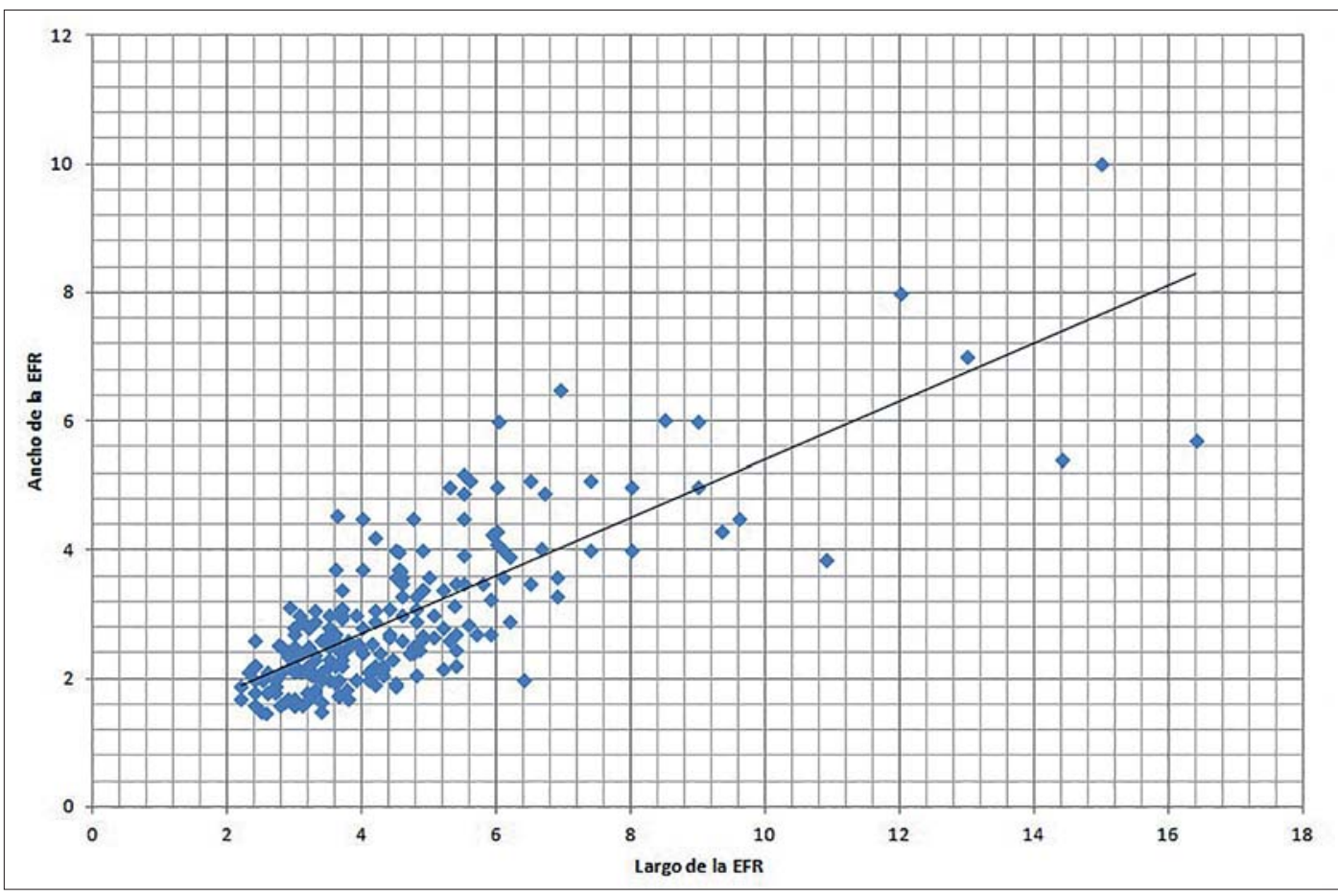

Fig. 3. Relación de los largos y los anchos de las EFRs peninsulares. / Relation between length and width in Iberian SFBs. valente al espacio efectivo de uso de las EFRs debido a la potencial existencia de un suelo sobreelevado de madera y a las distorsiones tafonómicas, aunque nos ofrece una idea del tamaño que podrían tener. Comparativamente con el caso francés, E. Peytremann ya sugirió la revisión de las dimensiones propuestas hacia una media en torno a los 4 y 14 $m^{2}$. Esta misma autora sugiere que los edificios de menor tamaño no sean caracterizados como EFRs sino como otro tipo de estructuras, así como aquellos mayores de $14 \mathrm{~m}^{2}$, que deberían ser considerados como "edificios excavados" (bâtiment excavé), es decir, estructuras tipológica y funcionalmente diferentes (PEYTREMANN, 2003: 275).

Por zonas geográficas ${ }^{10}$ parece que las EFRs de Madrid y Castilla y León, al menos en términos métricos, son más parecidos entre sí que con respecto a los de Cataluña, donde se concentran las EFRs de mayor tamaño y que, como veremos, responde a una tipología de estructuras de fondo rehundido complejas que, aunque detectadas en toda la Península, parece tener mayor distribución en esta zona (Tabla II).

Un análisis morfotipológico de esta estructura debe realizarse con precaución debido a la importancia de los procesos tafonómicos (vid. supra). Para su caracterización utilizaré la propuesta del difundido trabajo de A. Vigil-Escalera en 2000, en el que se utiliza como criterio tipológico principal de estas estructuras la forma excavada de la parte rehundida (tabla III), diferenciando de forma básica entre estructuras "ovaladas" y "(sub) rectangulares/cuadrangulares", dividiendo estas últimas entre las que presentan esquinas angulosas o redondeadas, mostrando las primeras más presencia de huellas de poste en los extremos axiales (VIGIL-ESCALERA, 2003a: 289). A esta clasificación, y a raíz del presente estudio, se han añadido algunas categorías que habrá que comprobar si son realmente significativas en posteriores análisis.

Teniendo en cuenta estas precauciones, y atendiendo a este criterio clasificatorio, obtenemos los resultados mostrados en la figura $4^{11}$. Los datos apuntan a una amplia mayoría de EFRs ovaladas sobre las de formato rectangular, si bien estas son también comunes en el registro. Hay que tener en cuenta, no obstante, que los procesos tafonómicos tenderían a "redondear" la estructura, y quizá muchas que en origen tenían un formato de lados rectangulares han llegado a nuestro tiempo con formato

\begin{tabular}{|c|c|c|c|}
\hline $\begin{array}{c}\text { Número de EFRs } \\
\text { analizadas }\end{array}$ & $\begin{array}{c}\text { MADRID } \\
137\end{array}$ & $\begin{array}{c}\text { CATALUÑA } \\
23\end{array}$ & CASTILLA Y LEÓN \\
\hline Largo-Ancho & $4,1-2,7$ & $7,2-4,6$ & 51 \\
\hline Área & $10,7 \mathrm{~m}^{2}$ & $38 \mathrm{~m}^{2}$ & $11 \mathrm{~m}^{2}$ \\
\hline
\end{tabular}

Tabla 2: Comparación métrica de las EFRs según la Comunidad Autónoma actual. Table 2: Comparative of SFBs mesures based on current Autonomous Community.

\footnotetext{
${ }^{10}$ Para este análisis se han tomado las circunscripciones administrativas actuales como forma más directa de comparación, aunque ya he comentado en otros trabajos que, al menos para la zona de Castilla y León, el uso de esta circunscripción para los análisis de la materialidad altomedieval no debería ser la norma, aunque nos permite algunas comparaciones útiles (TEJERIZO GARCÍA, 2012).

${ }^{11}$ Esta clasificación y análisis está basada en un total de 409 estructuras individualizadas cuya forma viene descrita, principalmente, por los informes y publicaciones al respecto y, de existir alguna foto o planta disponible, por el criterio del autor.
} 


\begin{tabular}{|c|c|c|c|c|}
\hline TIPO & SUBTIPO & MORFOLOGÍA & DIMENSIONES & ESTRUCTURAS ADOSADAS \\
\hline \multirow[t]{3}{*}{ A } & A1 & Ovalada & $2,4-3,7 \mathrm{~m} \cdot\left(7 \mathrm{~m}^{2}\right)$ & Sí (contenedores y hornos; agujeros de poste, nichos laterales. \\
\hline & A2 & Ovalada / irregular & Superior a $7 \mathrm{~m}^{2}$ & No. Se sitúan separadas. Posible presencia de entrada \\
\hline & A3 & Arriñonada & - & $\begin{array}{ll} & \text { No. }\end{array}$ \\
\hline \multirow[t]{4}{*}{ B } & B1 & Subrectangular en ángulos vivos & $5,7-8,5 \mathrm{~m}^{2}$ & No. \\
\hline & B2 & Subrectangular en ángulos redondeados & $4,5-10 \mathrm{~m}^{2}$ & Sí (hornos). Posible presencia de entrada \\
\hline & B3 & Subrectangular & $>10 \mathrm{~m}^{2}$ & Sí (hornos). Posible presencia de entrada \\
\hline & C1 & Irregular & $>10 \mathrm{~m}^{2}$ & $\begin{array}{l}\text { No. Conformada por la presencia de varias } \\
\text { estructuras excavadas yuxtapuestas }\end{array}$ \\
\hline C & C2 & Irregular & $>10 \mathrm{~m}^{2}$ & Sí. Estructuras de horno. \\
\hline
\end{tabular}

Tabla 3: Tipología a partir de Vigil-Escalera, 2000. En negrita, las tipologías nuevas propuestas. / Table 3: Typology based on Vigil-Escalera, 2000. In bold type, new typologies proposed.

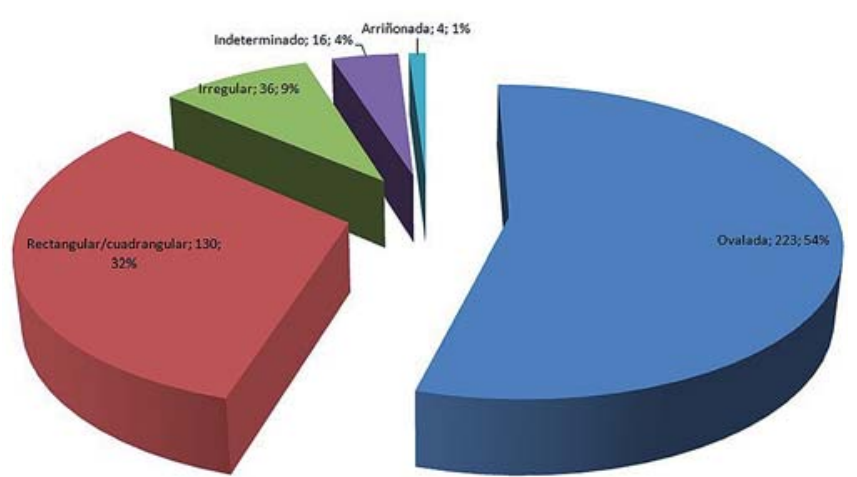

Fig. 4. Gráfico con las distintas formas de EFRs. / Chart of Iberian SFBs typologies.

ovalado (figuras 5 y 6). Un estudio detallado de la geología de los contextos podría acotar este problema en el futuro. En cualquier caso, parece obvio que en la Península Ibérica existe una particular heterogeneidad que no parece corresponder a la relativa homogeneidad de otros contextos, como el francés o el anglo-sajón (PEYTREMANN, 2003; HAMEROW 2012: 31). De hecho, es interesante que en la mayoría de los contextos en los que se han podido documentar una cantidad significativa de estas estructuras, como en Gózquez, El Pelícano o Buzanca 2, prácticamente todas las tipologías están representadas y usadas de forma contemporánea, mientras que en otros contextos, como La Mata del Palomar o Cárcava de la Peladera, parece existir una cierta homogeneización tipológica (TEJERIZO GARCÍA, 2012).

En la mayoría de los casos las EFRs son estructuras simples compuestas de un único rebaje en el suelo. Sin embargo, en algunas ocasiones observamos la presencia de EFRs complejas compuestas por dos o más cubetas adosadas unas a otras, muchas veces de forma irregular como ocurre en los yacimientos de Gózquez, Congosto, Canto Blanco, Can Gambús, Can Roqueta o en Plaça Major del Castellar del Vallès. En el ejemplo de la EFR 6940 de Gózquez parece que fue en inicio una EFR rectangular ampliada posteriormente. En otros casos, como la EFR 5555 de Gózquez nos encontramos con complejos compuestos por varias estructuras, en este caso, por la EFR, una cubeta horno adosada y tres fosas adyacentes de planta curvilínea. La interpretación de este tipo de estructuras es difícil y podría deberse tanto a motivos de formación del registro, estructurales (ampliaciones) como funcionales (espacios de trabajo específicos que generan formatos irregulares)

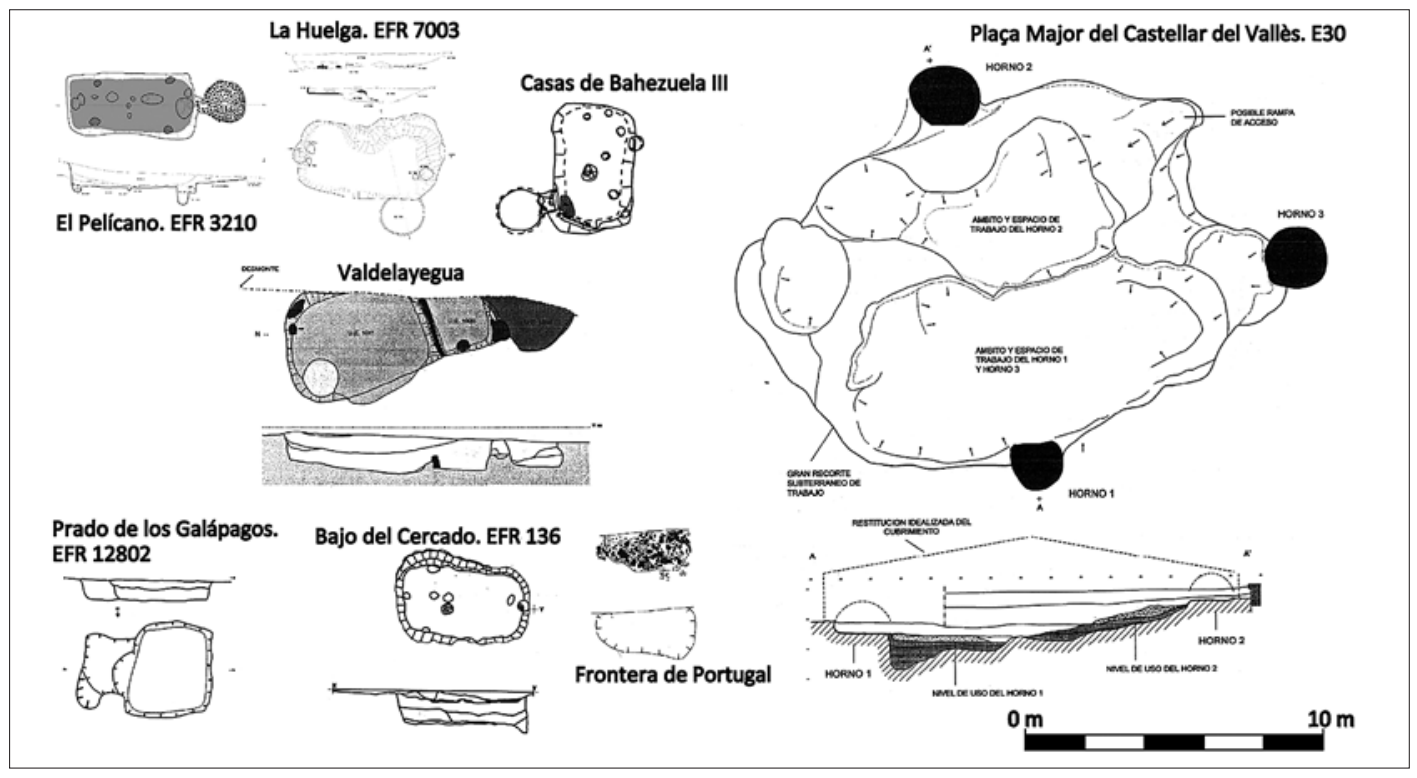

Fig. 5. Ejemplos de EFRs en la Península Ibérica. / Examples of SFBs in the Iberian $\mathrm{Pe}$ ninsula. 


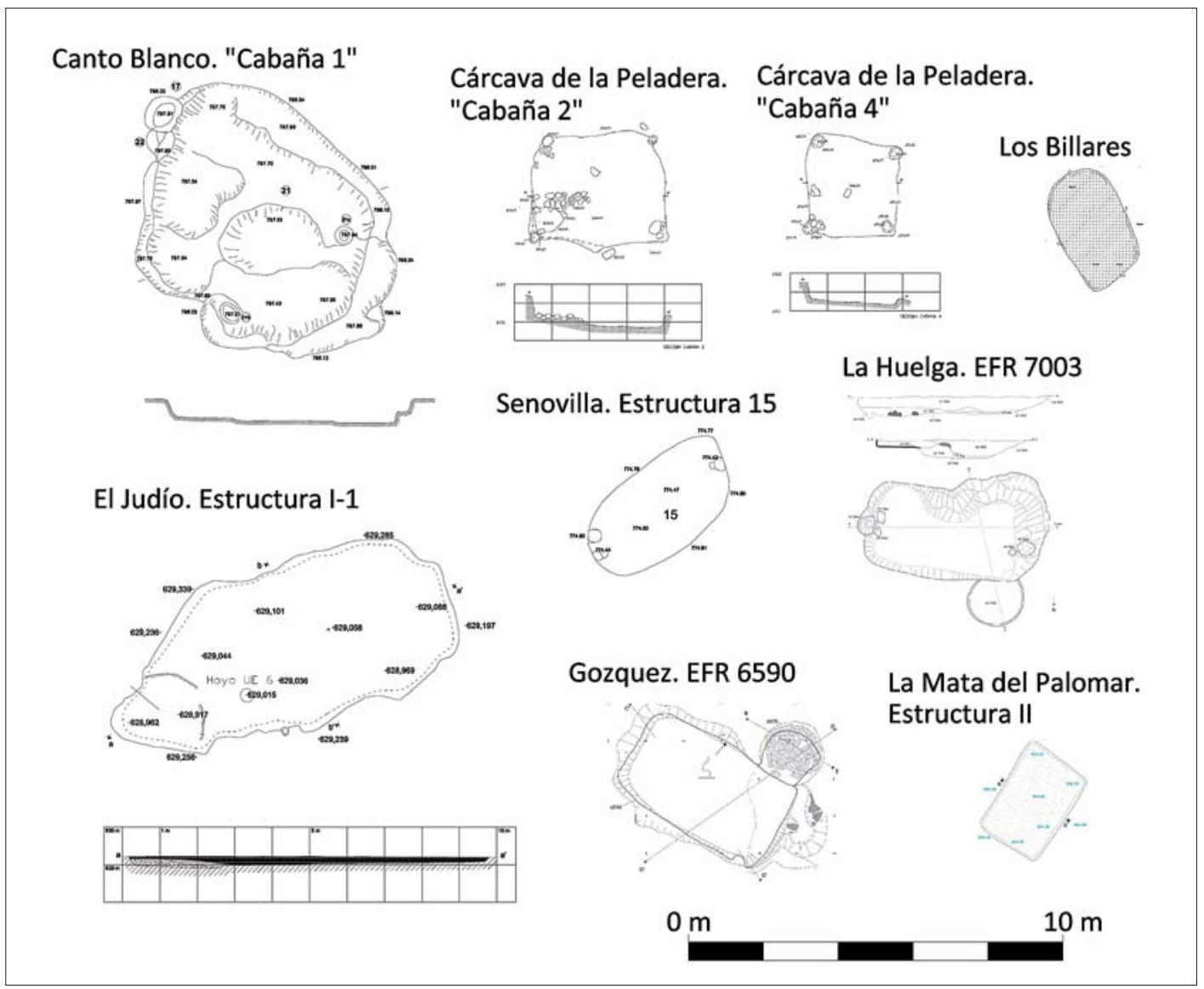

Fig. 6. Ejemplos de EFR en la Península Ibérica (II). / Examples of SFBs in the lberian Peninsula (II).
En el caso de algunos yacimientos como Ladera de los Prados, Canto Blanco y La Indiana, yacimientos en los que se disponía de una información cualitativa mejor, se ha observado una forma particular que ha sido denominada como "arriñonada" y que se caracterizaría por una forma ovalada achatada en uno o ambos lados mayores, si bien su interpretación se nos escaparía por el momento y podría estar en relación a la presencia de un suelo sobreelevado y el uso de la parte inferior como almacen.

La presencia de agujeros de poste y su disposición ha sido considerado otro de los elementos caracterizadores de este tipo de estructuras así como uno de los criterios clasificatorios más difundidos a partir de los trabajos de Ahrens (AHRENS, 1966) o Donat (DONAT, 1980), y que ha gozado de una amplia aceptación en Francia (CHAPELOT, 1980; PEYTREMANN, 2012). En el caso peninsular, se han podido detectar hasta 93 EFRs que presentan agujeros de poste asociados que, dentro del conjunto total de estructuras, no supone un número especialmente elevado, en torno a un $23 \%$. De 53 de ellas contamos con el número de agujeros documentados, representados en la figura 7.

Aunque cuantitativamente, la presencia de dos agujeros de poste en el eje axial de la estructura parece ser "predominante" (19 estructuras detectadas en 8 yacimientos, 7 de ellas en el yacimiento de Gózquez), lo que predomina cuantitativamente es su ausencia o la irregula- ridad en su disposición. Ausencia que podría deberse a diversas razones de orden tafonómico (desaparición de la evidencia de agujeros de poste al exterior de la estructura rehundida) o estructurales (uso de apoyos sobre el suelo para posicionar el poste, como se ha detectado en La Mata del Palomar). Destaca la bajísima cantidad de estructuras con 4 agujeros de poste en cada esquina (únicamente 6 casos en 5 yacimientos distintos, 2 de ellos en Cárcava de la Peladera) y de 6 agujeros de poste, que serían las estructuras mayoritarias en otros contextos europeos (DONAT, 1980; PEYTREMANN, 2003). Por otra parte es posible que algunos de estos agujeros de poste puedan representar mobiliarios, como en el caso de la "cabaña 3" de Cárcava de la Peladera, que presenta tres pequeños agujeros de poste alineados en la esquina noroccidental o como en la EFR E30 de Plaça Major en Castellar del Vallès. Sin embargo, los ejemplares peninsulares se alejan mucho de otros casos en los que se han llegado a detectar hasta 200 agujeros de poste, como en EFRs del yacimiento islandés de Hjálmsstađir (MILEK, 2012).

La simplicidad de la cadena operativa asociada a esta estructura tiene como consecuencia que en la mayor parte de las ocasiones las estructuras de fondo rehundido sean abandonadas o derribadas deliberadamente una vez dejan de ser útiles. Sin embargo, en algún caso la presencia masiva de estos agujeros de poste ha sido inter- 


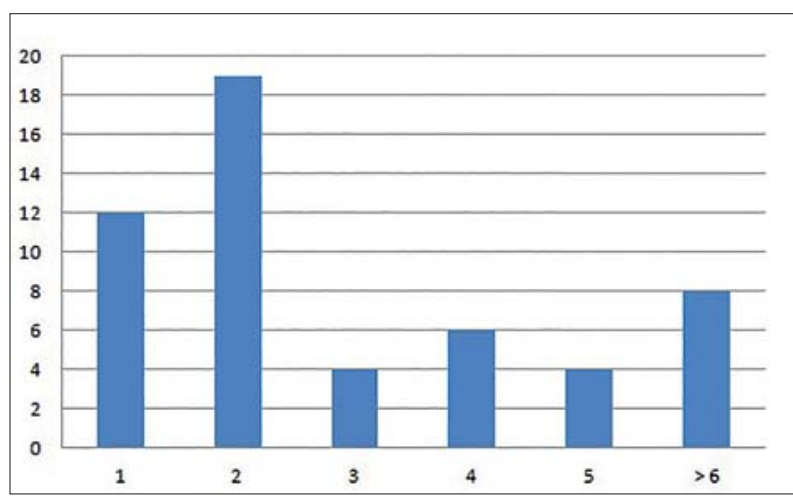

Fig. 7. Número de agujeros de poste en las EFR. / Number of postholes in SFBs.

pretada como diversas fases de utilización de la estructura o reparaciones. Este podría ser el caso de algunas EFR de Madrid como en El Bajo del Cercado (cabaña 192, con 5 agujeros de poste), Gózquez (cabaña 5200, con 10 agujeros de poste) o en Congosto (cabaña 1060 de Congosto, con 5 agujeros de poste). Este tipo de evidencias indican que, frente a un hipotético carácter marginal y temporal, esta estructura en ciertos contextos presenta un alto grado de estabilidad y fijación del espacio, como ha sido interpretado por algunas autoras como H. Hamerow (HAMEROW, 2012: 36)

La presencia de agujeros de poste en el exterior de la estructura mostraría la presencia de sustentantes perimetrales. Esta solución constructiva se ha documentado en pocas ocasiones aunque, dada su dispersión, sería una solución común. Únicamente se han detectado estructuras de este tipo en Gózquez (cabaña 5290, con un agujero de poste en el exterior alineado con el resto) con una parte de la estructura que excedería el propio hoyo; dos en Canto Blanco; dos en el yacimiento de Ca l'Estrada y otro en Plaça Major de Castellar del Vallès, con cerca de 12 agujeros de poste perimetrales. Es muy posible que la falta de estructuras de este tipo, muy corrientes en otros contextos, como el italiano (con ejemplos muy significativos en Poggibonsi o Donoratico) (VALENTI, 2007), se deba a la pérdida de cota como consecuencia de los procesos postdeposicionales y de excavación (Vid. supra).

Sin embargo, hay que considerar que abordar tipológicamente una estructura como la que aquí estamos analizando conlleva una enorme dificultad no solo debido a la influencia de los procesos tafonómicos y postdeposicionales sino también a la cuestión de la propia utilidad de realizar tipologías sobre una estructura que se caracteriza precisamente por su heterogeneidad. ¿Hasta qué punto nos ofrece información histórica una tipología sobre este tipo de estructuras? A pesar de lo necesarios que son los sistemas clasificatorios y las tipologías para el desarrollo de la Arqueología, nunca hay que olvidar, como nos advierte J. Deetz, que las tipologías son enteramente formales y en cierta medida arbitrarias y a las que llegamos independiente de lo que el usuario o productor del objeto percibió como diferentes tipos (DEETZ, 1996 [1ª ed. 1977]: 18). Siguiendo a L.F. Bate, un tipo útil a la investigación debe poseer dos propiedades esenciales: identidad y significado. Un tipo posee "identidad" cuando puede ser consistentemente identificado a través de sus propiedades sensorialmente perceptibles. Lo cual depende de una adecuada definición o descripción del mismo. El significado se refiere, a su vez, a la "significación" y la "relevancia"; la significación puede ser intuitiva, empírica o estadística, mientras que un tipo es relevante cuando tiene un significado conocido en relación a determinados propósitos (BATE, 1998: 17).

Efectivamente, la forma de la estructura rehundida es un criterio "significativo" en cuanto que es la única característica que podemos diferenciar "sensorialmente" en estas estructuras, si bien no es "relevante" por sí misma. Hasta el momento no se han podido hacer correlaciones significativas entre la forma y su función o significado contextual. Aunque esta tipología es la única útil en términos de clasificación a priori, dado que la forma del fondo es lo único que queda en el registro arqueológico, por sí misma no ofrece información útil para la interpretación de las propias estructuras más allá de su clasificación instrumental. Observamos por tanto, que si bien existen algunas tendencias generales, como la presencia de estructuras ovaladas de pequeño tamaño y sin agujeros de poste, las limitaciones en la clasificación e interpretación de estas estructuras bajo este tipo de criterios restringidos son evidentes. Es por ello necesario incluir otras variables que sí permitan complejizar el análisis, como son los aspectos estructurales relacionados con las cadenas tecnológicas operativas o las cuestiones de ordenación espacial.

\subsection{Aspectos estructurales}

Para abordar el análisis estructural de las estructuras hundidas se ha tomado como eje su cadena tecnológica operativa (sensu LEMONNIER, 1992) dada su potencialidad para generar información sobre la estructura social y simbólica a partir del registro arqueológico. A partir de un análisis de conjunto se podría considerar que la cadena tecnológica operativa más común de estas estructuras domésticas sería relativamente similar, si bien no exenta de complejidades. La propia elección del lugar donde posteriormente se realizaría el hoyo a partir de la cota de frecuentación del sitio ya implica una elección social y funcionalmente determinada, pues puede ser un entorno vacío de estructuras o cerca de otra ya amortizada y a la que en ocasiones sustituiría, lo que implicaría en cierta medida una capacidad de elección del usuario en función de las estructuras ya existentes y las necesidades a cubrir, así como la propiedad (privada o comunitaria) del espacio edificable. La evidencia material parece mostrar que en primer lugar se instalarían los postes para la sustentación de la cubierta y posteriormente se acondicionaría el suelo, normalmente de tierra apisonada. En el caso de que el suelo estuviera sobreelevado, se colocarían las tablas de madera aprovechando los extremos del hoyo excavado.

Sobre esta base rehundida, característica diferenciadora de esta estructura, se levantaría la parte superior de 
la estructura que debió ser fundamentalmente de tierra reaprovechando seguramente la tierra ya excavada. De esta manera, las estructuras de fondo rehundido serían fundamentalmente arquitecturas de tierra, aspecto que reviste de cierta complejidad tanto estructural como en reconocimiento arqueológico (SÁNCHEZ, 1999; ROHMER, 1989). La variedad constructiva debió de ser grande a juzgar por los datos arqueológicos, pero la evidencia parece señalar que el sistema más habitual para la construcción de estas estructuras sería el de tapial mediante sistemas de encofrado de madera y revocados posteriormente con barro (SÁNCHEZ, 1999: 169). En este sentido, el análisis de los rellenos y la falta de evidencias de agujeros o fundaciones en torno al fondo rehundido sugerirían la ausencia generalizada de técnicas de manteados sobre entramados lígneos (wattle-and-daub en la literatura anglosajona), muy comunes en ámbito europeo y especialmente en el anglosajón (DIXON, 1995; DONAT, 1980; PEYTREMANN, 2003: 275; HAMEROW, 2011, 2012; WEST, 1986). Esto señalaría una diferencia clara con el contexto peninsular donde hay una ausencia significativa de EFRs con las paredes construidas a partir de un entablado de madera salvo por la excepción de algunas estructuras documentadas en la catedral de Santa María en Vitoria-Gasteiz (AZKÁRATE y SOLAUN BUSTINZA, 2012), así como la presencia de posibles manteados en el yacimiento de Zaballa evidenciados por algunos revestimientos de arcilla con improntas de postes (ALFARO, 2012). Excepciones cuya localización geográfica podrían estar señalando una forma constructiva diferenciada, como ya sugerimos en otro trabajo (TEJE$\mathrm{RIZO}, 2012)$. Igualmente, las evidencias del uso generalizado de adobes para la construcción de estas estructuras son muy efímeras; al igual que la teja, la presencia de adobes es común en los rellenos excavados de las estructuras (se ha detectado en al menos 37 estructuras), pero dadas las cuestiones tafonómicas ya descritas, así como las cuestiones relacionadas con la cadena operativa concreta del adobe (SÁNCHEZ, 1999: 171-172), su uso debe tomarse con precaución. En cualquier caso, sobre esta construcción en tierra se colocaría la techumbre a través de un sistema de ramajes y material vegetal que se puede combinar, potencialmente, con otros elementos como la teja o la pizarra si bien no debieron ser el material principal frente a los materiales perecederos.

Un aspecto que ha sido objeto de debate es la disposición de la cota de frecuentación y del suelo de las EFRs. La irregularidad en la detección de los suelos, entre otras variables, llevó a algunos autores como S. West a sugerir la existencia de una cota de uso sobreelevado de madera por encima del suelo rehundido (HAMEROW, 2012: 58; WEST, 1986). Otras evidencias que sugerirían esta solución estructural serían el escaso tamaño de las áreas rehundidas, la homogeneidad estratigráfica de los estratos inferiores de estas estructuras, la presencia de hogares que sobrepasan la estructura y la evidencia de tablas de madera quemadas conservadas en el registro de algunas estructuras en yacimientos como West Stow (TIPPER, 2004: 77 y ss.). Si bien en este yacimiento se documenta- ron algunos casos que parecían evidenciar la presencia de estos suelos sobreelevados, otros contextos coetáneos muestran pruebas de los contrario, como en Mucking (ARNOLD, 2000 [3rd edition]: 41). En el caso peninsular no existe un número muy amplio de EFRs en las que se haya podido documentar un suelo a pesar de que tenía que ser una solución estructural muy común. Donde sí ha podido documentarse, suele tratarse de una superficie preparada con una capa de arcilla endurecida (en ocasiones a través de su calentamiento, como en la estructura 1000 de Valdelayegua) y apisonada. Una solución para el suelo de estas estructuras atípico se encuentra en el yacimiento de La Mata del Palomar, con suelos hechos con esquistos de pizarra local. En este sentido se podría mencionar el caso de una estructura de Valdelayegua, cuyo suelo irregular y la presencia de agujeros de poste "pueden permitir plantear la existencia de un suelo de madera que permitiera utilizar el espacio inferior como bodega" (PRESAS VIAS, et al., 2009: 358). Todo parece indicar, por tanto, que estas dos soluciones fueron utilizadas de forma contemporánea (HAMEROW, 2011: 149 y ss.), aunque los datos arqueológicos parecen apuntar a que el uso del fondo rehundido como cota de frecuentación sería mayor.

Un elemento significativo en algunas EFR y que también mostraría este uso del fondo rehundido como suelo es la presencia de estructuras de combustión, hogares y hornos principalmente. En la Península Ibérica, debido a los procesos tafonómicos, postdeposición y excavación, su conservación y diferenciación es extremadamente rara (VIGIL-ESCALERA, 2012). Para el presente análisis únicamente se han detectado una treintena de hogares en EFRs en 18 yacimientos diferentes y, generalmente, en un estado muy deficiente de conservación o únicamente intuido en la excavación a partir de estratos de ceniza dentro de la amortización de la EFR. Los pocos casos bien documentados muestran una gran variedad: en el caso de la estructura 560-566 en Congosto el hogar se encontraba al sur de la cabaña mientras que en la E30 de Plaça Major en Castellar del Vallès se localizó en un lateral, delimitado por Iosetas; en Pla del Serrador el hogar se encontraba ligeramente excavado en una de las paredes de la fosa aunque su asociación con un nicho/horno podría indicarnos su uso como horno y no como hogar; en el yacimiento de CanGambús se ha podido documentar un hogar con solera hecha de fragmentos de tegulae y dolia; finalmente, en Cárcava de la Peladera encontramos una EFR con un muro que delimita un hogar en la zona suroccidental de la EFR. Por otro lado, en el yacimiento de Frontera de Portugal, el hogar detectado "compuesto por una fosa rectangular que corta a la cabaña por el noroeste, localizándose su relleno tanto en su interior, como esparcido por la cabaña" (SÁNCHEZ SÁNCHEZ-MORENO y GALINDO SAN JOSÉ, 2006) podría sugerir la presencia de una EFR de suelo elevado.

La presencia de hornos en las EFRs es relativamente frecuente y supone un rasgo bastante singular del contexto peninsular, aunque no exclusivo. Se han podido documentar cerca de 40 EFRs con hornos en 16 yacimientos distintos (Figura 8). Como definió A. Vigil-Escalera, se trata 


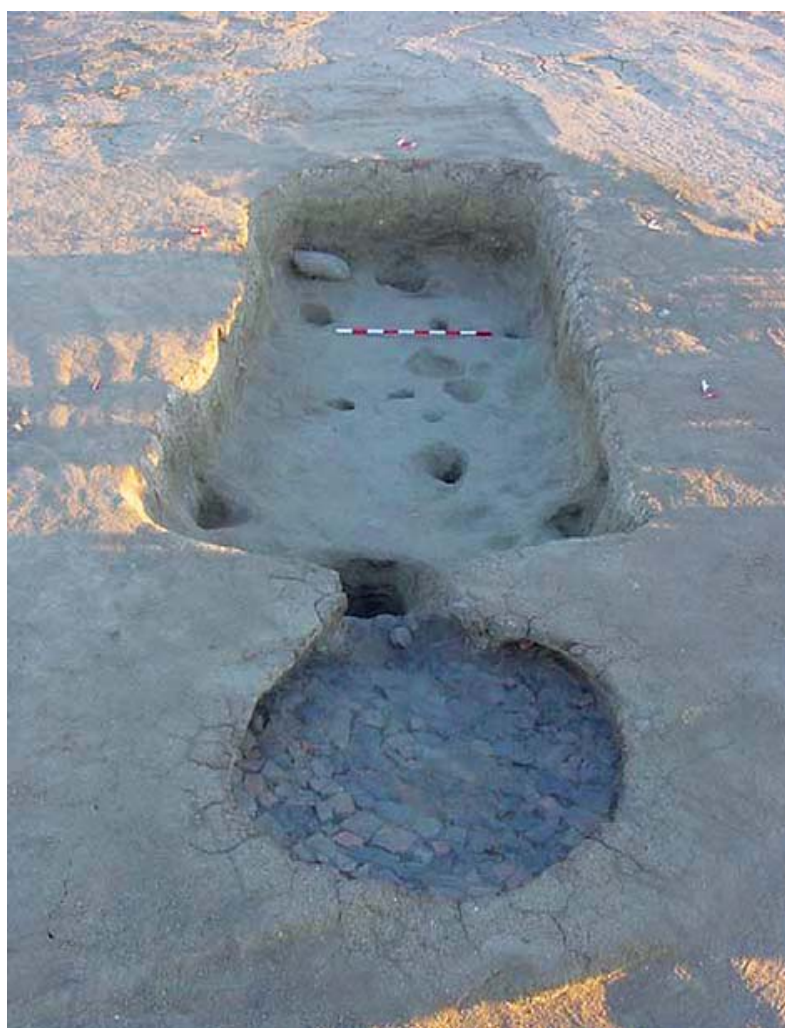

Fig. 8. EFR 3210 en el Pelícano (Vigil-Escalera, 2003). / SFB 3210 from E Pelícano (Vigil-Escalera, 2003).

de estructuras normalmente "de cámara hemisférica excavada parcial o totalmente en el sustrato geológico. La cavidad sirve a la vez de cámara de fuego y de cocción. El horno se asocia siempre a una fosa de trabajo delante de su embocadura, que permite la manipulación en el interior de la cámara" (VIGIL-ESCALERA, 2012: 166). Estos se encuentran normalmente adosados a la EFR como una estructura anexa a la que se accede a través de la EFR, como se documenta en Gózquez (estructura 6575, por ejemplo; Figura 9) o adosada en la parte final de uno de sus lados largos, como ocurre en el yacimiento de Casas de Bahezuela III, La Huelga o en algunos ejemplares de Gózquez. En cualquiera de los dos casos, parecen localizarse fuera del propio ámbito doméstico relacionado seguramente con la salida de humos de la estructura y para facilitar su uso desde el interior. En algunas estructuras se ha podido determinar que la instalación del horno se produce en un segundo momento de uso, que suele implicar transformaciones estructurales importantes en la EFR, como se ha podido determinar en La Huelga, Gózquez o el Pelícano (VIGIL-ESCALERA, 2003b, 2012).

Estos hornos pueden documentarse internos a estructuras complejas, como ocurre en la estructura 1715 de Prado de los Galápagos, en la EFR 5740 de Gózquez o en el caso de la interesante estructura compleja E15 de Plaça Major de Castellar del Vallès. Esta ha sido identificada como un área especializada en la elaboración del pan; se trata de un gran recorte de cerca de $140 \mathrm{~m}^{2}$ de planta elíp- tica en el que se sitúan tres hornos con sus correspondientes zonas de trabajo. Estos hornos tendrían una planta circular y sección hemiesférica con una solera plana y paredes de arcilla (ROIG BUXÓ, 2009; ROIG BUXÓ y COLL RIERA, 2010). Al respecto de este tipo de complejos, se ha sugerido que la presencia de varios hornos en un mismo entorno podría no ser coetánea sino producto de los ciclos de construcción y reconstrucción de los hornos (VIGIL-ESCALERA, 2012: 177), como se ha mostrado en contextos franceses de forma reiterada (BRULEY-CHABOT, 2007), la estratigrafía asociada a la estructura de Gózquez parece ser clara a este respecto.

Estas estructuras con horno asociado han sido relacionados con el amasado y cocción del pan de las unidades domésticas (BRULEY-CHABOT, 2007), lo que descartaría otros usos coetáneos diferentes (VIGIL-ESCALERA, 2012: 179). Este uso privado de estas estructuras podría combinarse con cierta producción especializada y artesanal en las estructuras más complejas, como la de Plaça Major del Castellar del Vallès, en el caso de pertenecer a una única fase. Igualmente, la presencia de silos en los alrededores inmediatos de las EFRs ha sido relacionada con el procesamiento y secado del cereal, aspecto relativamente común en los yacimientos de la Península Ibérica como en el caso de la estructura 6073 de El Pelícano. También la documentación de hoyos internos a la EFR podrían estar relacionados con el almacenamiento en el interior de las cabañas de productos alimentarios dentro de contenedores construidos con fibras vegetales trenzadas (VIGIL-ESCALERA, 2000: 231). En otros casos, como en Canto Blanco, la presencia de estructuras rehundidas se ha relacionado con la gestión del agua y la presencia de pozos en el interior de estas (STRATO, 2010), como también se documenta en algunos yacimientos catalanes.

A pesar de que la entrada a las estructuras domésticas es uno de los elementos más interesantes a la hora de analizar la organización espacial de las aldeas (HAMEROW, 2012: 37 y ss.), en el caso peninsular se cuenta con muy pocas evidencias. De aquellos casos que se ha podido determinar un poco mejor su ubicación (tabla IV) se observa que esta podía realizarse desde prácticamente cualquier parte de la estructura dependiendo de las condiciones geoclimáticas y espaciales del contexto aunque con cierta preferencia por la zona sur de la estructura:

En relación a la entrada de estas estructuras, algunas presentan una pequeña ampliación en uno de los lados cortos que podría ser una especie de vestíbulo de entrada, como se sugiere para el hoyo 54 de El Pelambre (GONZÁLEZ FERNÁNDEZ, 2009). Estructuras con similares rebajes adosados se han documentado en Valdelayegua (EFR 1200) y Prado de los Galápagos (EFR 12802 y EFR 5502) con paralelos en Europa, como en Sutton Courtenay, Dorchester-on-Thames o Tilleda (DIXON, 1995; TIPPER, 2004: 81 y sS; CHAPELOT Y FOSSIER, 1980: 120).

La variedad en la cadena operativa de estas estructuras también se observa en el uso de materiales de dis- 


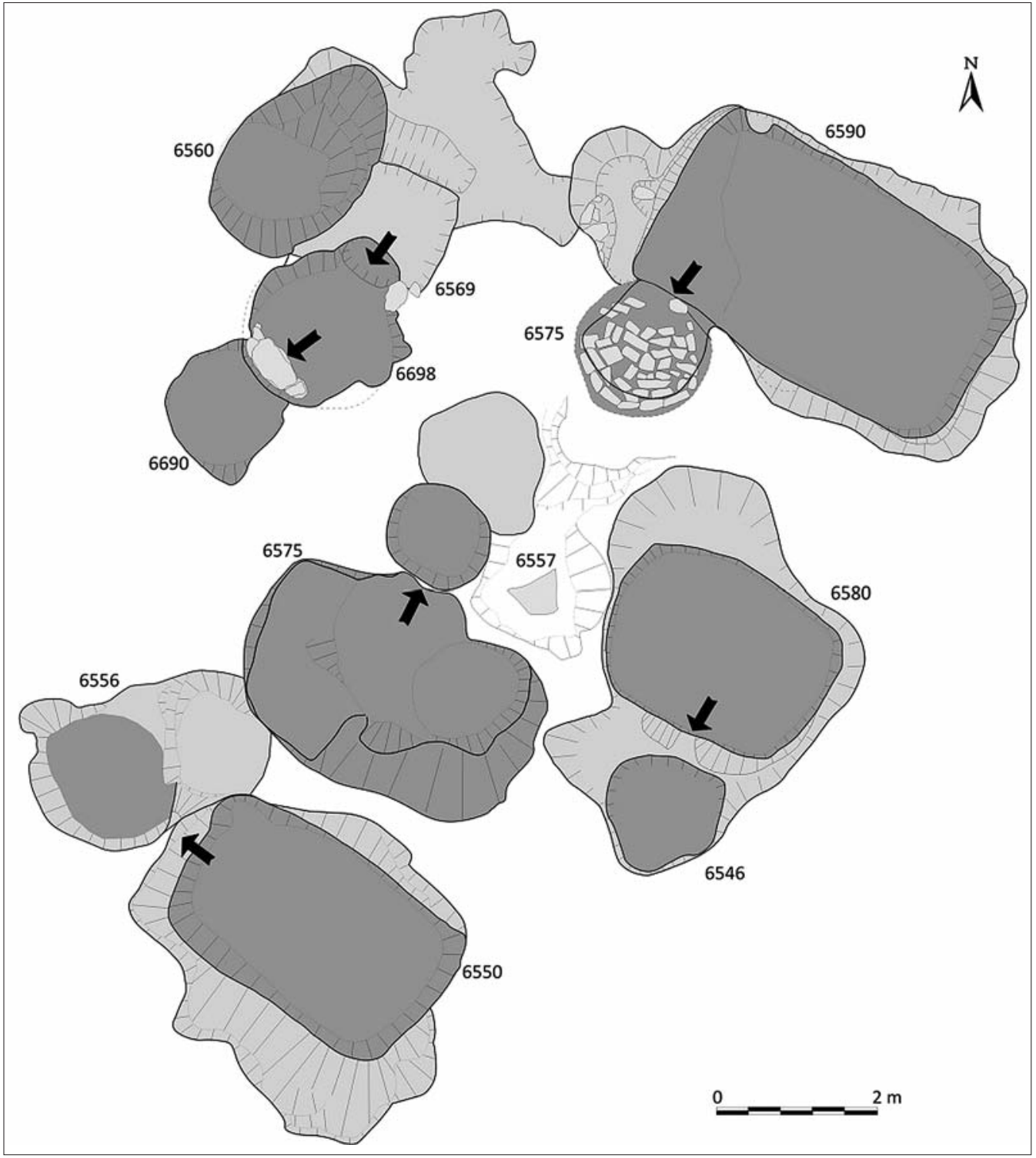

Fig. 9. Acceso a las estructuras de combustión en el complejo 6545 de Gózquez (Vigil-Escalera, 2012). Access path to kilns in 6545 complex in Gózquez (Vigil-Escalera, 2012).

\begin{tabular}{|c|c|}
\hline SITUACIÓN DE LA ENTRADA RESPECTO A LA EFR & No $^{\circ}$ de EFRs \\
\hline N & 1 \\
\hline S & 4 \\
\hline E & 1 \\
\hline W & 1 \\
\hline NE & 2 \\
\hline NW & 2 \\
\hline SE & 3 \\
\hline SW & 2 \\
\hline N/NE/NW & 5 \\
\hline S/SW/SE & 9 \\
\hline
\end{tabular}

Tabla 4: Localización de las entradas en las estructuras de fondo rehundido. Table 4: Location of the entrances to sunken featured buildings.

tinta naturaleza. La presencia de muros de piedra interiores a las EFRs compartimentando el espacio a modo de muro sustentante es cada vez más frecuente y se detecta en yacimientos de amplia diversidad regional como Góz- quez, (donde, por ejemplo, la colocación de un muro interior de piedras de yeso sin desbastar en una EFR dejó inutilizada parte de la estructura), La Mata del Palomar, Indiana, Prado de los Galápagos o Camp Vernell. Esta compartimentación interior también puede hacerse a través de manteados de barro, como ocurre en la estructura 1000 de Valdelayegua. También se documenta la presencia de bancos corridos de piedra en un lateral de la estructura en yacimientos como Gózquez o La Mata del Palomar. En el caso de El Guijo se detectaron varias EFRs cuyos derrumbes internos parecían indicar la presencia de muros de piedra en el lado oeste de las estructuras a modo de parapetos para la protección de las estructuras (REDONDO GÓMEZ, et al., 2006: 483). Las estructuras descritas para Zarautz Jauregia también parecen combinar diversas cadenas tecnológicas (SARASOLA ETXEGOIEN, 2011) así como algunas detectadas en las excavaciones de la catedral de Santa María en la actual Vi- 
toria-Gasteiz (AZKÁRATE y SOLAUN BUSTINZA, 2012). En contextos europeos la combinación de cadenas tecnológicas y materiales parece ser una solución relativamente común, como se muestra en el caso de los yacimientos de Montours en Francia (CATTEDDU, 2001).

En este sentido se puede citar el caso de la casa P01A de El Pelícano, con una división tripartita y un uso mixto de materiales analizada en un reciente trabajo y del que destaca la presencia de un bloque con una parte delimitada por una roza simple en el terreno y planta rematada en curva, estructura única en el contexto peninsular (VIGIL-ESCALERA, 2012: 172) pero con paralelos europeos, como en el yacimiento francés de Yutz (BLAISING, 2000). Una estructura similar fue excavada parcialmente en el yacimiento de Valdelayegua. La estructura E12 de Zaballa, aunque de características diferentes, también presenta la combinación de una estructura aérea en cuyo interior parece inscribirse una estructura de fondo rehundido (ALFARO, 2012). La presencia de EFRs vinculadas a derrumbes masivos de piedra en la Cárcava de la Peladera podrían hacer referencia a la combinación en una misma estructura de estructuras de suelo rehundido con estructuras aéreas de piedra, aunque su documentación no es clara (STRATO, 1999). Por último, los excavadores del yacimiento de Els Mallols también apuntan a que es posible que las estructuras de fondo rehundido sean construcciones en el interior o bajo otras más importantes a modo de almacenes, lo que explicaría la ausencia de agujeros de poste o suelos (FRANCÈS I FARRÉ, 2007: 81).

En cuanto a la techumbre, todo parece apuntar a que se realizaría a través de un entramado vegetal, como ya se apuntó. Sin embargo, existen algunos registros que plantean posibles alternativas. Un caso particularmente significativo a este respecto es el de Frontera de Portugal (Barajas, Madrid), donde se detectaron potentes derrumbes de teja que pudieron pertenecer a la techumbre de las dos EFRs documentadas (SÁNCHEZ SÁNCHEZ-MORENO y GALINDO SAN JOSÉ, 2006). Este yacimiento no sería el único contexto en el que se documenta una cantidad abundante de teja asociado a los rellenos de esta arquitectura doméstica (otros ejemplos serían La Mata del Palomar, Canto Blanco o El Pelícano, por mencionar algunos ejemplos). Sin embargo, únicamente se ha documentado su uso como techumbre de forma segura en las construcciones sobre zócalo de piedra, faltando todavía un registro claro que permita afirmar el uso de teja en las estructuras de fondo rehundido. En el caso de La Mata del Palomar, la masiva presencia de pizarra en los rellenos de las EFRs podría indicar también su uso en la techumbre como forma de impermeabilización ${ }^{12}$.

\subsection{Cuestiones espaciales}

Una vez descritas las características morfotipológicas y estructurales más comunes de las EFR, cabe pregun- tarse por sus patrones de aparición, esto es, dónde y cómo aparecen en el registro arqueológico.

En primer lugar, hay que destacar aquellos tipos de asentamientos en los que no se han documentado. Principalmente hay que hacer mención a los entornos "urbanos" (con todas las reservas para el uso del concepto de "ciudad" o de "urbanismo" para el período comprendido entre los siglos V y X) (WICKHAM, 2005: 591-596) y a las ocupaciones en altura. En el caso de las ocupaciones en altura anteriores al siglo $X$, no solo hay ausencia de estructuras de fondo rehundido, sino en general de todo tipo de estructura negativa, al menos en el estado de conocimiento actual, debido a que la mayoría se sitúa en entornos geológicos poco aptos para su construcción. Más interesante es quizá su ausencia en contextos urbanos. En ninguna de las ciudades con excavaciones estratigráficas más o menos extensas se ha documentado ninguna de estas estructuras negativas, aunque sí otras, como estructuras tipo silos, como ocurre en Vega Baja en Toledo o en el barrio de Morerías, en Mérida.

La asociación de "cabañas" con la ocupación de las villas tardoimperiales también ofrece muchos problemas, si bien se ha afirmado su presencia de forma extensa en varios contextos (CHAVARRÍA ARNAU, 2006) por el momento se cuentan con pocos casos publicados y todos ellos muy dudosos, como serían los casos de las villas de Vilauba (Camós, Gerona), El Val (Alcalá de Henares, Madrid), Veranes (Gijón; únicamente con un hogar y un agujero de poste asociado y posiblemente posteriores ambos al siglo VIII) (FERNÁNDEZ OCHOA, et al., 2005-2006), Tinto Juan de la Cruz (Pinto, Madrid) y la estructura registrada en el yacimiento de Las Pizarras (Coca, Segovia). En prácticamente todos ellos se ha asociado la presencia de estas estructuras "efímeras" a poblaciones "marginales" (o squatters) reutilizando los espacios vilicarios, sin embargo, las últimas excavaciones llevadas a cabo en Vilauba parecen apuntar hacia otras interpretaciones.

En la villa de Vilauba (Banyoles, Girona) se documentó en las excavaciones de finales de los 70 e inicios de los 80 una serie de agujeros de poste asociados a una prensa, posiblemente de aceite, y que fueron interpretados como una pequeña cabaña de planta rectangular. Una cabaña relacionada con los últimos momentos previos al abandono definitivo de la villa en el siglo VII y que se asoció a una ocupación de "squatters" en la villa (CASTANYER MASOLIVER y TREMOLEDA TRILLA, 2001-2002). Sin embargo, las nuevas excavaciones han puesto al descubierto un complejo residencial compuesto por tres unidades domésticas conformadas por un patio, una estructura central de habitación y una estructura anexa. Estas estructuras se construyeron con cantos rodados trabados con mortero y cuyos espacios centrales tenían uno o dos hogares adosados a las paredes. No se documentó en todo este

\footnotetext{
12 Un uso este de la pizarra para la techumbre, denominado arquitectura negra, que ha sido muy común en la arquitectura vernácula de la zona hasta hace relativamente poco tiempo (VELA COSSÍO, 2002: 26).
} 
complejo ninguna estructura negativa, ya sean estructuras de fondo rehundido, cubetas o estructuras tipo silos (CASTANYER MASOLIVER, et al., 2013). Todos estos datos invitan a replantear la presencia de una cabaña en el interior de la villa, que, en cualquier caso, sería una estructura aérea de postes de madera y no de perfil rehundido. Hay que recordar que la presencia de estructuras de postes es extremadamente rara en el contexto peninsular, salvo algunos casos, excepcionales, del norte peninsular y de momento ausentes en el centro peninsular (TEJERIZO GARCÍA, 2012). Es más probable que los agujeros de madera se relacionaran con el acondicionamiento del espacio para la instalación de estructuras productivas en un momento de transformación de la villa tardoimperial, como podría también ser el conocido caso de la ocupación de la sala del Auriga en la villa de El Val (RASCÓN MARQUÉS, et al., 1991) o Tinto Juan de la Cruz (BARROSO CABRERA, et al., 2001: 202), asociados en su momento a poblaciones "bárbaras" que instalarían cabañas en el interior de los espacios de la villa. Sin embargo, la parquedad de las informaciones arqueológicas sobre los contextos de excavación así como los materiales asociados con ellos suponen un importante problema a la hora de su interpretación que, a la luz de los avances realizados en el estudio de las ocupaciones aldeanas de la Alta Edad media, deberían revisarse. El caso de Vilauba y las estructuras domésticas recientemente excavadas parecen evidenciar esta necesidad de revisión del carácter "marginal" de este tipo de evidencias. La publicación de los materiales asociados a estos contextos y su cronología, podrían resolver satisfactoriamente este problema.

El caso de Las Pizarras es algo distinto, ya que sí contiene una estructura de fondo rehundido en el contexto de una villa tardoimperial, aunque alejada de sus dependencias. Sin embargo, la descripción publicada ofrece algunas dudas para adscribirla como estructura de fondo rehundido según el tipo-ideal descrito aquí, como su gran tamaño (cerca de $40 \mathrm{~m}^{2}$ ), la presencia de hoyos-contenedores de vasijas de almacén, la presencia de un suelo compuesto por fragmentos de ladrillo y la amortización del espacio por una tumba datada en torno al siglo VI, "en las postrimerías de la Edad Tardoantigua" (PÉREZ GONZÁLEZ y REYES HERNANDO, 2012-2013: 221)13. Es muy posible que nos encontremos ante una estructura anterior en el tiempo y seguramente asociada con el propio funcionamiento de la villa, quizá en sus últimas fases de uso. Los intensos expolios a los que se vio sometido el entorno a partir del siglo VNI debieron de desmantelar y arrasar esta zona de la pars rustica de la villa, desvirtuando y arrasando esta estructura, originalmente con un fondo rehundido. Hay que destacar sin embargo, que en otros entornos de la villa se han excavado silos de almacenamiento que denotan un asentamiento rural altomedieval, de nuevo, sin poder datar con precisión y que, estos sí, estarían asociados a los enterramientos sobre la villa (PÉREZ GONZÁLEZ y REYES HERNANDO, 2003). La publicación de fotografías o del material asociado a los estratos de relleno de la misma sin duda permitirán en el futuro delimitar su cronología y su función.

Todas las estructuras aquí analizadas, por tanto, se han documentado en asentamientos rurales abiertos, espacios en los que parecen tener un "sentido" (funcional, estructural y simbólico) completo. Como muestran los contextos mejor excavados, su distribución es relativamente homogénea en cuanto que no se detectan concentraciones de estas estructuras, como ocurre en Gózquez, El Pelícano o Canto Blanco (figura 10). De producirse algunas concentraciones de estructuras, como ocurre en La Mata del Palomar, habría que relacionarlo fundamentalmente con el desarrollo de las unidades domésticas dentro de los espacios aldeanos (figura 11).

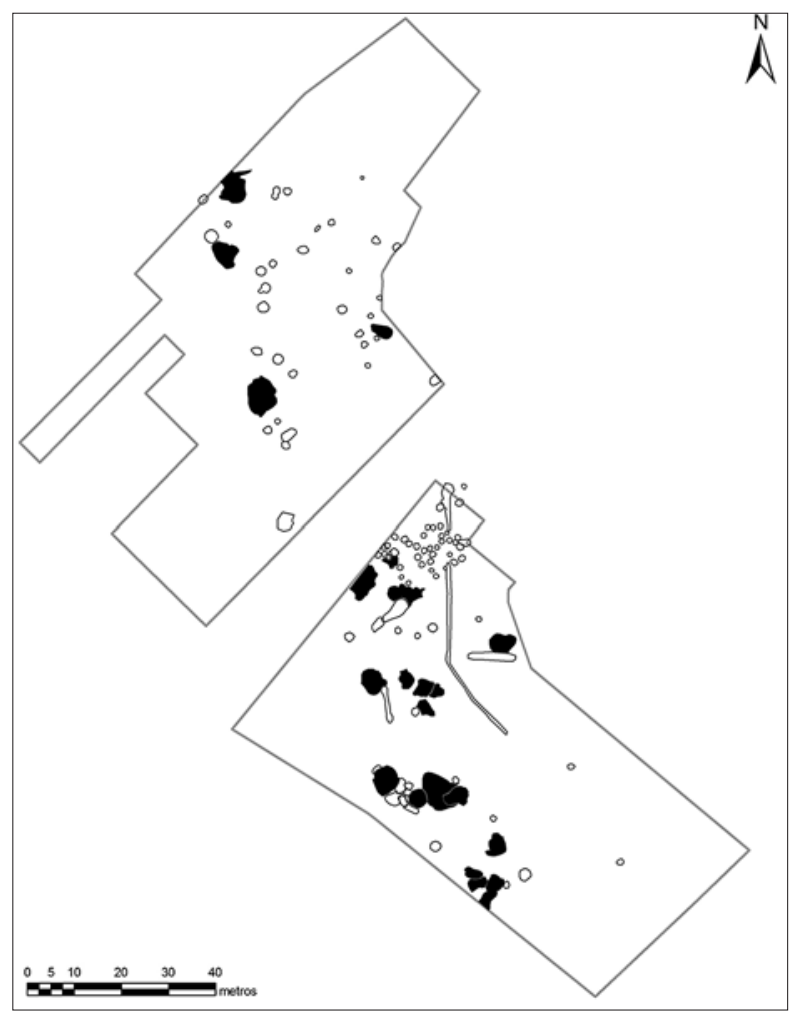

Fig. 10. Estructuras de fondo rehundido altomedievales en Canto Blanco. Sunken Featured Buildings in Canto Blanco.

En estos asentamientos la arquitectura doméstica se compone fundamentalmente del uso contemporáneo de estas estructuras de perfil rehundido en asociación con estructuras aéreas, cuya relación estructura la propia composición de las unidades domésticas. Actualmente está ya suficientemente demostrada la coexistencia temporal de estos dos tipos de arquitectura doméstica desde mediados del siglo V en contextos aldeanos como Gózquez, El Pelícano o Carratejera (QUIRÓS CASTILLO, JUAN AN-

\footnotetext{
${ }^{13}$ La superposición de un cementerio sobre espacios domésticos en este período no se ha documentado por el momento.
} 


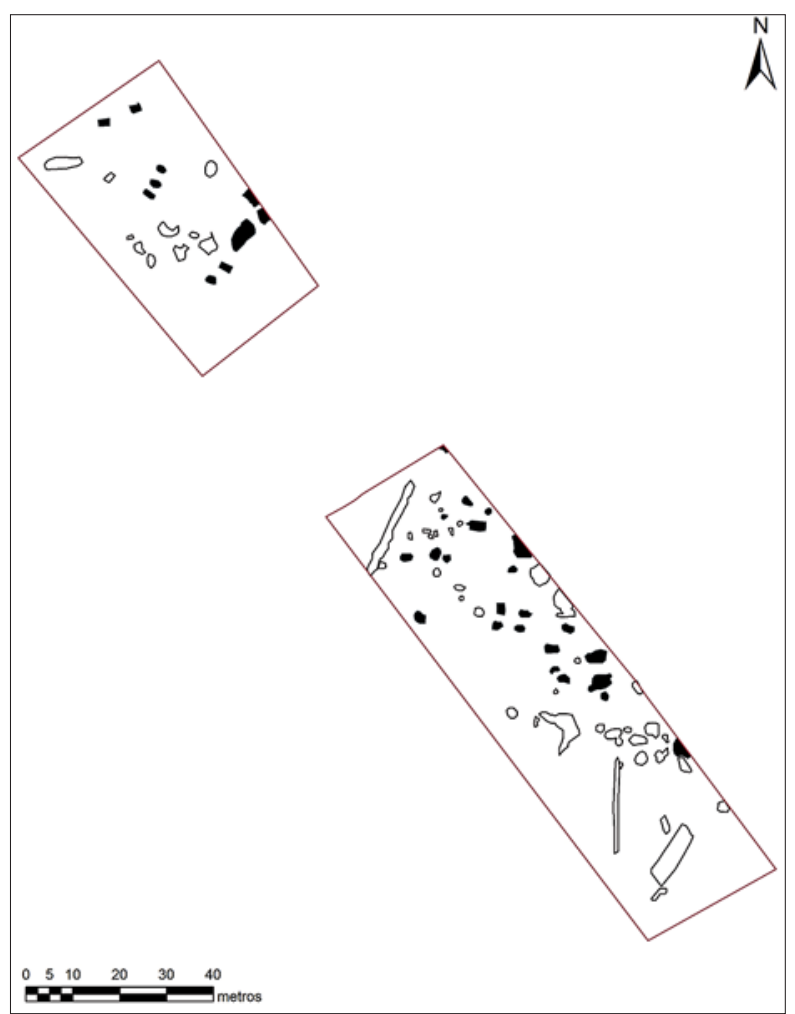

Fig. 11. Estructuras de fondo rehundido en La Mata del Palomar. / Sunken Featured Buildings in La Mata del Palomar.

TONIO, 2011; TEJERIZO GARCÍA, 2012) por lo que sobra su discusión en este trabajo.

La relación cuantitativa y espacial de estos dos tipos de estructuras ha sido un aspecto analizado en profundidad en el contexto anglosajón (tabla V), que han determinado una variedad importante de situaciones desde la presencia de cuatro estructuras de fondo rehundido por cada estructura aérea en el yacimiento de Mucking hasta una EFR por cada 14 estructuras aéreas en el yacimiento de Chalton (ARNOLD, 2000 [3rd edition]; JAMES, et al., 1984). En este caso o en Cowdery's Down, parece existir una relación regular entre los dos tipos de estructuras en cuanto que la EFR se sitúa paralela al edificio principal, conectadas por las entradas (JAMES, et al., 1984: 198). Esta diferencia de proporciones ha sido puesta en relación a la geología así como a la organización de las unidades domésticas; así, parece evidente que el ratio de EFRs con respecto a estructuras aéreas es menor en suelos compuestos por calizas duras y mayor en zonas de gravas y arcillas, aunque con excepciones notables, como el yacimiento de Yeavering o el de Old Down Farm (ARNOLD, 2000 [3rd edition]: 51-52; TIPPER, 2004: 24-25).

El patrón regular observado con frecuencia es la presencia de una estructura aérea como núcleo principal en torno a la cual se disponen las estructuras de fondo rehundido a modo de grupos (clusters). Así parecen mostrar los análisis realizados en yacimientos como West Stow, Catholme o Mucking (ARNOLD, 2000 [3rd edition]: 50; TIPPER, 2004).

En el caso de la Península Ibérica todavía no se dispone de la suficiente información publicada como para elaborar un cuadro completo sobre este aspecto (tabla $\mathrm{VI}$ ). Sin embargo, algunos yacimientos situados en zonas llanas basadas geológicamente en deposiciones sedimentarias tipo margas y arcillas parecen mostrar en todos los casos una mayor relevancia cuantitativa de las estructuras de fondo rehundido sobre las estructuras aéreas, aunque estos datos podrían estar distorsionados por los procesos tafonómicos y postdeposicionales que hayan destruido parte de las estructuras aéreas conocidas.

Para el caso de Gózquez (San Martín de la Vega, Madrid) se ha planteado un modelo de poblamiento consistente en la presencia de cerca de una docena de unidades domésticas cuya arquitectura doméstica comprendería

\begin{tabular}{|c|c|c|c|c|c|c|}
\hline YACIMIENTO & ESTRUCTURAS AÉREAS & \% ESTRUCTURAS AÉREAS & EFRs & \% EFRS & RATIO & SUBSTRATO GEOLÓGICO \\
\hline Mucking & 53 & 20,3 & 207 & 79,7 & $1: 4$ & Gravas \\
\hline West Stow & 14 & 16,8 & 69 & 83,2 & $1: 5$ & Arcillas \\
\hline Old Down Farm & 0 & 0 & 6 & 100 & $6: 0$ & Caliza \\
\hline Barrow Hills & 22 & 32,8 & 45 & 67,2 & $2: 1$ & Gravas \\
\hline West Herleston & 90 & 40,9 & 130 & 59,1 & $1.4: 1$ & Arcillas \\
\hline Puddlehill & 0 & 0 & 9 & 100 & $9: 0$ & Caliza \\
\hline Pennyland & 3 & 18,8 & 13 & 81,2 & 4.3:1 & Gravas \\
\hline Catholme & 65 & 79,2 & 17 & 20,8 & $1: 3,8$ & Gravas \\
\hline Bishopstone & 19 & 86,3 & 3 & 13,7 & $1: 6,3$ & Caliza \\
\hline Abbots Worthy & 0 & 0 & 5 & 100 & $5: 0$ & Caliza \\
\hline Eynsham & 4 & 19 & 17 & 80.9 & $1: 4$ & Grava \\
\hline Cowdery's Down & 18 & 90 & 2 & 10 & $8: 1$ & Caliza \\
\hline Chalton & 57 & 93,4 & 4 & 6,6 & $14: 1$ & Caliza \\
\hline Wijster & 86 & 38 & 140 & 62 & $1: 1,6$ & - \\
\hline Flögeln & 40 & 50 & 40 & 50 & $1: 1$ & - \\
\hline Warendorf & 65 & 48 & 70 & 52 & $1: 1$ & - \\
\hline Kootwijk & 45 & 20 & 177 & 80 & $1: 4$ & - \\
\hline
\end{tabular}

Tabla 5: Relación cuantitativa entre las EFR y las estructuras aéreas en contextos europeos datos según ARNOLD, 2000: 47; TIPPER, 2004 y CHAPELOT Y FOSSIER, 1985. Table 5: Quantitative relationship between SFB and aerial structures in European contexts according to ARNOLD, 2000: 47; TIPPER, 2004 and CHAPELOT and FOSSIER, 1985. 


\begin{tabular}{|c|c|c|c|c|c|}
\hline YACIMIENTO & $\begin{array}{c}\text { ESTRUCTURAS } \\
\text { AÉREAS }\end{array}$ & $\begin{array}{c}\text { \% ESTRUCTURAS } \\
\text { AÉREAS }\end{array}$ & EFRs & $\begin{array}{c}\% \\
\text { EFRS }\end{array}$ & RATIO \\
$\begin{array}{c}\text { La Mata } \\
\text { del Palomar }\end{array}$ & $\begin{array}{c}\text { ¿9-10? } \\
\text { Gózquez }\end{array}$ & 30 & 22 & 70 & $1: 2$ \\
\hline El Pelícano & 14 & 20 & 69 & 80 & $1: 4$ \\
\hline Congosto & 3 & 24 & 44 & 76 & $1: 3$ \\
\hline
\end{tabular}

Tabla 6: Relación cuantitativa entre las EFR y las estructuras aéreas en contextos peninsulares. / Table 6: Quantitative relationship between SFB and aerial structures in Iberian contexts.

una o más estructuras aéreas a las que se asociarían de 3 a 5 estructuras de fondo rehundido a modo de estructuras productivas auxiliares para tareas como la cocción del pan. Casos similares, con una estructura aérea a modo de "estructura singular" a la que se asocian un número variable de estructuras de fondo rehundido pueden detectarse en otros yacimientos de Madrid como Congosto, El Pelícano o, de forma más indirecta, Quintano (VIGIL-ESCALERA, 2009).

Se trataría de un modelo más común de lo que habitualmente se plantea para zonas como la cuenca del Duero. El yacimiento de La Mata del Palomar (Nieva, Segovia) podría ser un ejemplo de este mismo modelo al norte de la sierra de Guadarrama. En este yacimiento se documentaron, algunas muy arrasadas y otras de forma indirecta a través de la presencia de suelos, hasta nueve estructuras aéreas. Aquellas mejor conservadas se conforman por lajas de pizarras trabadas con barro a las que se asocian entre 2 y 4 estructuras de fondo rehundido y 1 o 2 silos. Situaciones similares se pueden encontrar en Cárcava de la Peladera (Hontoria, Segovia), La Huesa (Cañizal, Zamora), Ladera de los Prados o Senovilla (Olmedo, Valladolid) (NUÑO GONZÁLEZ, 2003; VIGIL-ESCALERA y STRATO, 2013).

\section{4.- DISCUSIÓN}

A la vista de los datos se pueden realizar algunas consideraciones generales sobre las estructuras de fondo rehundido en cuanto a su cronología, su funcionalidad dentro del contexto peninsular altomedieval así como una interpretación histórica sobre su aparición. Tradicionalmente se ha asociado la aparición de estas estructuras con la llegada de pueblos "alóctonos" que trasladarían sus formas tradicionales de arquitectura doméstica (BROGIOLO y CHAVARRÍA ARNAU, 2008; VALENTI, 2007, 2009). Interpretación que tiene cierto éxito en la Península Ibérica a la hora de analizar estas estructuras (p. ej BARROSO CABRERA, et al., 2001; o RODRÍGUEZ CIFUENTES y JUANA GARCÍA, 2006). Dos son los argumentos principales para sostener esta línea interpretativa: por un lado, la "novedad" de estas formas constructivas, ausentes en épocas anteriores a finales del siglo V; y, por otro, la coincidencia temporal con las "invasiones" referidas en las fuentes escritas y la frecuencia de estas estructuras "en asentamientos donde se puede plantear la hipótesis de la presencia alóctona con base en otros parámetros", como son los rituales de enterramiento (BRO-
GIOLO y CHAVARRÍA ARNAU, 2008: 202). Sin embargo, el análisis de los datos expuestos permite sugerir líneas interpretativas alternativas.

En primer lugar se trataría de hacer una crítica arqueológica y cronológica sobre las estructuras de fondo rehundido con el fin de enmarcar, y relativizar, su presencia en los contextos altomedievales. Estructuras cuya característica definitoria es la presencia de un fondo rehundido se detectan desde épocas prehistóricas en toda Europa Occidental. En la Península Ibérica los ejemplares más antiguos se pueden datar incluso en el Neolítico como el documentado en La Deseada (Madrid) (DÍAZ DEL RíO y CONSUEGRA, 1999). Su proliferación se produce, sin embargo, durante el Calcolítico y a lo largo del Bronce e incluso en momentos de Hierro I en yacimientos como Barranco del Herrero (San Martín de Vega, Madrid) (MORíN DE PABLOS, et al., 2006), La Huelga (Dueñas, Palencia), Tolmos de Caracena (Soria), Caserío de Perales o Fábrica de Ladrillos (ambos en Getafe) (SÁNCHEZ POLO, 2011 (inédito)). Se trataría de estructuras que, a primera vista, podrían ser similares con las aquí analizadas en época altomedieval, si bien con diferencias estructurales y, sobre todo, diferencias en relación al contexto arquitectónico y espacial. Sin embargo, esta semejanza ha llamado la atención de algunos autores, que han sugerido una vuelta o resurgimiento de las comunidades indígenas a sus antiguas formas constructivas, obviando con ello casi cinco siglos de dominio imperial romano. Bajo mi punto de vista, esta semejanza tiene más que ver con modos de producción similares, aunque bajo formaciones sociales y modos de vida (sensu BATE, 1998) distintos.

Un elemento que se ha subrayado de forma recurrente es la aparente ruptura en las tradiciones constructivas entre el mundo tardoimperial y el postimperial. Sin embargo, este panorama dista mucho de ser unívoco. En Inglaterra, estructuras que incorporan estructuras negativas en su construcción se han localizado en yacimientos como Monkton (Kent), datados en el siglo II d.C o en Dalton Parlours (Yorkshire), datados entre el siglo III y el IV d.C. En este último sitio se excavó una estructura (structure $P$ ) cuyos lados, excavados en el terreno, estaban parcialmente revestidos con piedras colocadas en seco. En su interior se encontraron estructuras como un horno, un molino y un hogar. Este edificio fue interpretado como una estructura ancilar para el procesado de cereal (TIPPER, 2004: 9). En Francia también se han documentado casos similares al anglosajón datados en el siglo IV d.C (PEYTREMANN, 2003). Este tipo de estructuras mostrarían tradiciones constructivas ya conocidas y utilizadas matizando una ruptura radical entre dos mundos constructivos. Algunos contextos como el del edificio romano de La Indiana (Pinto, Madrid), datado entre finales del siglo II e inicios del siglo III, podrían hacer referencia a este tipo de arquitecturas mixtas (VIGIL-ESCALERA, 2007a), así como el ya analizado ejemplar de Las Pizarras, que podría responder a este modelo.

En cualquier caso, parece evidente a la luz de los datos que la máxima expansión de este tipo de estructuras se produce entre los siglos $\vee y$, fundamentalmente en 
los siglos VI y VII. Más en concreto, algunas EFRs se pueden datar sin problema hacia mediados del siglo V (si no ya dentro de esta primera mitad de la quinta centuria), como ocurre en Carratejera (STRATO, 2003), Loranca o El Pelícano. En contextos del centro peninsular, muchas desaparecerían con el abandono de los contextos aldeanos a mediados del siglo VIII, consecuencia de la imposición del poder político islámico (VIGIL-ESCALERA, 2007b), mientras que otras permanecerían aún durante algunas generaciones más, como ocurre en la "fase emiral" del yacimiento de El Esparragal, en Pinto (Madrid) (CONTRERAS MARTÍNEZ, et al., 2007) o en el yacimiento de El Soto/Encadenado. La reorganización del poblamiento rural en época califal explicaría en gran medida la desaparición masiva de estas estructuras durante el siglo IX o tal vez el siglo $X$

A partir de este momento el número de EFRs se reduce progresivamente, manteniéndose, sobre todo, en el extremo norte de la cuenca del Duero y en el área catalana. El fin del uso generalizado de estas estructuras se dataría, en el estado actual de conocimiento, en torno al siglo XI o XII, como ocurre en Canto Blanco o incluso posteriormente, en yacimientos como Can Gorgals Vell o Cal Ticó, en Cataluña (FOLCH IGLESIAS, et al., 2009: 294).

Estas cronologías coinciden con las manejadas para los contextos europeos, si bien con diferencias y matices regionales. Por ejemplo, En Francia parece que su inicio se encuentra en el siglo IV, aunque se difunden a partir del siglo $\mathrm{V}$, extendiéndose al norte hacia la sexta centuria, marcando su final hacia el siglo X/XI o incluso posteriormente, llegando al siglo XIV (CHAPELOT y FOSSIER, 1985 [ $1^{\text {a }}$ ed 1980]: 133; PEYTREMANN, 2003: 277). En el caso anglosajón, su inicio se data fundamentalmente en el siglo $V$ y su desaparición del registro se ha datado en el siglo XII (TIPPER, 2004: 14). En Italia estas estructuras parecen usarse, principalmente, entre finales del VI/VII y el VIII (FRONZA, 2009; VALENTI, 2007: 461). En Islandia estas estructuras se datan principalmente en el siglo IX y XI, relacionándose su final con profundos cambios políticos, económicos y culturales relacionados con la entrada del cristianismo y el modo de producción feudal (MILEK, 2012).

Aunque la aparición masiva en el registro arqueológico de las estructuras de fondo rehundido parece tener un punto de inflexión entre los siglos XII-XIV su uso siguió siendo común en un gran número de sociedades incluso hasta épocas recientes. En el caso de Norteamérica, estructuras con el fondo rehundido han sido utilizadas frecuentemente desde hace 4200 años llegando incluso a los siglos XVIII-XIX (SPRINGER y LEPOFSKY, 2011). También en Europa ha sido un tipo de estructura frecuente hasta épocas muy recientes; en Holanda ha sido utilizada como arquitectura doméstica de familias de clase baja y en In- glaterra como establo y almacén hasta el siglo XIX (HAMEROW, 2002) así como en Rumanía como estructura de habitación hasta bien entrado este siglo (CHAPELOT y FOSSIER, 1985 [1 $1^{a}$ ed 1980]: 125). Estudios etnográficos parecen relacionar, aunque no de forma estricta, la utilización de estructuras de fondo rehundido y sociedades con un grado reducido de estratificación social y organización política (GILMAN, 1987: 548).

Esta variabilidad cronológica, geográfica y cultural de las estructuras de fondo rehundido obliga a contextualizar de forma rigurosa su utilización a la hora de interpretar su uso por las sociedades altomedievales peninsulares y no vincularlas de forma directa a ciertas etnias o pueblos concretos sin realizar un análisis más complejo.

Como se ha mostrado, la expansión de este tipo de estructuras se produciría a partir del siglo V sin una geografía específica, apareciendo de forma ubicua a lo largo del centro y norte peninsular ${ }^{14}$, coincidiendo no tanto con la entrada masiva de pueblos alóctonos si no con la desarticulación del entramado económico imperial romano basado en las grandes propiedades vilicarias, datado a lo largo del siglo V (CHAVARRÍA, 2006). Esta desarticulación económica y social tuvo profundas consecuencias en los patrones de poblamiento, cuya transformación más significativa fue el encuadramiento de la mayoría de la población en granjas y aldeas y, como consecuencia, la extensión de sociedades de tipo campesino (QUIRÓS y VIGIL-ESCALERA, 2006). Esta expansión de las formas de producción campesinas tuvieron importantes implicaciones a la hora de estructurar las formas de vida concretas de las distintas poblaciones, incluida la forma de concebir la arquitectura doméstica, cuyo rasgo estructural más característico, sobre todo en comparación con el anterior periodo romano, fue la simplificación de las cadenas operativas asociadas (AZKARATE y QUIRÓS CASTILLO, 2001).

La hipótesis que se presenta entonces es que, en el contexto altomedieval peninsular, hay que asociar el uso de las estructuras de fondo rehundido a la expansión de formas productivas concretas en las que encontraría un sentido funcional y simbólico coherente. En concreto, se trataría de una estructura asociada a las sociedades campesinas previas a la expansión de las estructuras de producción feudales ${ }^{15}$ (WICKHAM, 2005: 442 y ss) cuya característica más definitoria sería la preeminencia de la unidad doméstica como lugar de producción y consumo así como de organización de la producción, y cuyos ciclos generacionales determinarían gran parte de su habitus social (BOURDIEU, 2000 [1 ${ }^{a}$ ed. 1972]; WOLF, 1966; CAMERON, 1991; GERRITSEN, 1999).

De esta manera se explicaría no solo su ubicuidad geográfica y temporal en el contexto altomedieval penin-

\footnotetext{
${ }^{14}$ En este sentido, J.A. Quirós cuestionó la relación de estas estructuras con poblaciones alóctonas en referencia a las estructuras de fondo rehundido documentadas en Estepona, Málaga, en el yacimiento de Lomo de Alberica/Arroyo Vaquero II, muy alejado del área de influencia "bárbara" (QUIRÓS CASTILLO, JUAN ANTONIO, 2011: 77).

${ }^{15}$ Lo que en otro trabajo definimos como "modo de producción campesino". Para una discusión de este término (TEJERIZO GARCÍA, $\left.2013 a\right)$.
} 
sular, sino también su aparición casi exclusiva en contextos rurales, excluidos de otros espacios, especialmente las ciudades y los centros de poder. En prácticamente todos los contextos rurales excavados en una cierta extensión en entornos geológicos sedimentarios esta estructura aparece de forma mayoritaria en el registro, siempre en asociación directa a las distintas unidades domésticas, como se muestra claramente en el caso de Gózquez, El Pelícano o La Mata del Palomar, por citar algunos ejemplos.

Este tipo de sociedades y sus estructuras sociales, económicas y mentales facilitarían y permitirían el desarrollo de este tipo de arquitectura, que habría que relacionar, no tanto como una "arquitectura étnica" sino como una "arquitectura vernácula campesina", tal y como ya planteaba en los años 50 Ralegh Radford para el caso anglo-sajón (RALEGH RADFORD, 1957). Una arquitectura que se caracteriza, precisamente, por su versatilidad, adaptabilidad y la escasa o ausente especialización en sus ciclos constructivos así como por su aparente similitud en amplios espacios geográficos, reflejo de que "el programa tipológico y constructivo es bien conocido por el usuario o consumidor, que tiene en el proceso de definición del edificio un peso específico muy importante" (VELA COSSÍO, 2002: 15). En este sentido hay que recordar que los constructores de este tipo de arquitecturas suelen ser sus propios usuarios y reflejan una visión social y comunitaria de la arquitectura, determinada (embedded) por la formación social en la que se inserta (RAPOPORT, 1972). Una arquitectura que mostraría un carácter profundamente localista, determinado por cuestiones como el uso de la materia prima local o las tradiciones constructivas, lo que genera una gran heterogeneidad al ampliar las escalas de análisis a pesar de que los elementos comunes se mantienen, esto es, perdurabilidad generacional y conservación (VELA COSSÍO, 2002: 14).

Todo lo enunciado (heterogeneidad, flexibilidad en las soluciones constructivas, uso de cadenas operativas poco complejas...) es coincidente con lo observado en las estructuras de fondo rehundido altomedievales y, por extensión, a gran parte de la arquitectura doméstica documentada en estos momentos. Las estructuras de fondo rehundido son tremendamente adecuadas para el desarrollo de una forma de vida campesina y sus procesos productivos. En primer lugar, la facilidad (relativa) de la cadena operativa asociada que se ha descrito permite que sus ciclos de construcción/reconstrucción sean asumibles por cualquier unidad doméstica, sin generar excesos de gasto económico o energético. Esta razón también explicaría su alto número en relación a las estructuras aéreas así como la atestiguada destrucción y posterior construc- ción de estructuras similares en espacios relativamente pequeños, como se documenta en Ladera de los Prados, Senovilla o Gózquez. En segundo lugar su versatilidad, pudiendo ser un espacio en el que desarrollar muchas tareas comunes tales como la producción auxiliar (textil, cocción del pan) o el almacenaje. Y, en tercer lugar, las propias ventajas climáticas, ambientales y estructurales que ofrece el suelo rehundido.

¿Cuál sería la función o las necesidades concretas que cubrirían estas estructuras en el contexto altomedieval? En su trabajo de síntesis, Tipper enumeraba una batería de funcionalidades potenciales incluyendo residencia doméstica, almacenes, hogares, telares, almacenes de grano, zonas de cocción de pan, etc. (TIPPER, 2004: 160) a la que se añadiría una posible función específicamente funeraria, como se ha sugerido para alguna EFR documentada en una de las necrópolis del yacimiento de Mucking (HAMEROW, 2011) así como algunas estructuras en el norte de Francia (PEYTREMANN, 2003). La ventaja funcional de este tipo de estructuras reside en las condiciones climáticas creadas en el espacio rehundido; así, estas permitirían una atmósfera y una humedad adecuada para la producción de tejidos (teoría defendida por HAMEROW, 2012 o MILEK, 2012), así como para otros procesos como la fermentación del queso y la conservación de la leche (CHAPELOT y FOSSIER, 1985 [1 $1^{a}$ ed 1980]: 127; GILMAN, 1987) ${ }^{16}$. En cualquier caso, la evidencia empírica parece mostrar un uso multifuncional de esta estructura, que, dependiendo del contexto doméstico en el que se inserte podría satisfacer unas necesidades u otras (o varias simultáneamente, como se documenta en Islandia (MILEK, 2012)). En el caso de la Península Ibérica, todo apunta a que, en primer lugar, se trataría de una estructura auxiliar complementaria a las unidades domésticas, cuyas estructuras residenciales se materializarían en la forma de estructuras aéreas con zócalos de piedra, descartando así su función como residencia principal, aunque existen multitud de ejemplos etnográficos que atestiguan este uso en otros contextos ${ }^{17}$. Por lo tanto serían estructuras esencialmente multifuncionales, destacando sobre todo las funciones de almacén, de producción textil, procesado del cereal y la cocción del pan, atestiguado por la presencia de hornos asociados.

Muy sugerente, aunque difícil de demostrar actualmente, es su vinculación con el trabajo subalterno de la mujer, y en concreto con el textil, propuesto por algunas autoras (HAMEROW, 2012; MILEK, 2012). En este sentido, cabe mencionar que en algunas de las colecciones legislativas altomedievales como la la Lex Salica (inicios de la sexta centuria) o la Lex Alamannorum (escrita en la séptima centuria) se hace referencia a multas por llevarse mujeres de una habitación cerrada o screona, lo que ha

\footnotetext{
${ }^{16}$ En concreto, la diferencia de profundidad con respecto a la cota de frecuentación permite la mantención de la temperatura constante: "heat losses from air filtering through house cracks and holes are greatly reduced or eliminated, and the termal mass of the soil reduces energy variation on the structure exterior and so reduces interior temperatura variations.. these houses are not subject to temperatura loss by wind" (GILMAN, 1987: 542).

${ }^{17}$ El Atlas etnográfico de Murdock recoge 84 grupos cuyo lugar de habitación principal o secundario es una estructura rehundida (GILMAN, 1987: 540-541)
} 
llevado a algunos autores a relacionarlas con estructuras de fondo rehundido y con la producción textil. Algo similar ocurre con menciones a genicium o cellaria, estructuras seguramente dedicadas al almacén e igualmente relacionado con el trabajo femenino (HAMEROW, 2002: 45-46). Arqueológicamente, la relación de las EFRs con actividades textiles se ha sugerido a través de dos marcadores: por un lado, la presencia conjunta de un número significativamente alto de pesas de telar con pequeños agujeros de poste que se relacionarían con la estructura del telar y del trabajo femenino. Estudios microestratigráficos como los realizados en una cabaña en el yacimiento de Hofstað̌ir, en el noreste de Islandia, parecen indicar que en esta cabaña se realizaba toda la cadena operativa relacionada con la producción textil, desde la obtención de la lana hasta su limpieza con orina, que se almacenaba en la misma cabaña (MILEK, 2012). Esta misma autora sostiene la hipótesis de que la desaparición de esta estructura guardaría relación con ciertas imposiciones del cristianismo contra los rituales de magia que ciertas mujeres realizarían en estructuras excavadas en el subsuelo. En segundo lugar, a través de estudios etnológicos se ha podido documentar la vinculación de la mujer a actividades relacionadas con las que se desarrollaron en el interior de estas estructuras como la cocción del pan (ALBIR HERRERO, 2010). El registro peninsular, por el momento, no permite sostener ni refutar esta hipótesis.

Si la aparición de esta estructura se vincula con la aparición de unas sociedades campesinas específicas, su práctica desaparición en torno al siglo XIII habrá que vincularla, pues, con su desarticulación progresiva. A medida que las estructuras políticas suprarregionales y el modo de producción basado en la extracción directa de renta (el modo de producción feudal) articularon un nuevo sistema de producción, más centralizado y con redes de distribución supra-aldeanas, así como una especialización progresiva, las formas descentralizadas de producción irán progresivamente desapareciendo. Este proceso reorientaría las formas productivas, de manera que las estructuras de fondo rehundido dejarían de tener una función estructural dentro de las aldeas o, dicho de otra manera, las tareas realizadas en ellas se trasladarían a otros espacios, más acordes con los nuevos contextos económicos y sociales, como podría ser el interior de las residencias domésticas o los centros de producción especializados. Se trataría de un proceso similar al que explicaría, por ejemplo, las transformaciones en los sistemas de almacenaje de este tipo de comunidades a lo largo de la Edad media (VIGIL-ESCALERA, et al., 2013) o la centralización política de la producción en los espacios de poder (QUIRÓS CASTILLO, J.A, 2011).

\section{5.- CONCLUSIONES}

A modo de recapitulación de lo ya expuesto, es importante destacar en primer lugar la importancia cuantitativa y cualitativa de las estructuras de fondo rehundido dentro de la materialidad de las sociedades altomedieva- les. Se trata de una estructura detectada de forma masiva en prácticamente todos los contextos rurales altomedievales y en toda Europa Occidental. Su ausencia en amplios ámbitos de la Península Ibérica se vincula principalmente a la ausencia de excavaciones en extensión, pero también con razones de orden geológico y socio-económico. Una estructura que, sin embargo, se ha mostrado que no es exclusiva ni de este período ni de esta región, aunque sí especialmente significativa en los primeros momentos de la Alta Edad Media.

En el caso de la Península Ibérica, su (tardío) "descubrimiento" ha provocado un aluvión de ejemplares procedentes de intervenciones en el ámbito de la arqueología comercial que, debido a la falta de sistematización, han sido en muchas ocasiones erróneamente clasificados y analizados. Un estudio detallado de sus características como el presentado en este trabajo creo que ayudará a facilitar su detección y caracterización en el futuro. Una estructura que, por las propias características de su cadena operativa, se ve ampliamente afectada por los procesos tafonómicos y postdeposicionales del registro arqueológico y que han supuesto una pérdida muy importante de información que es necesario tener en cuenta a la hora de analizarla arqueológica e históricamente así como al plantear futuras intervenciones.

A pesar de la similitud en las características morfotipológicas generales de estas estructuras con respecto a otros paralelos europeos, el conjunto de EFRs documentados en la Península Ibérica parece denotar una heterogeneidad muy significativa en cuanto a sus aspectos formales y estructurales, si bien existen tendencias morfotipológicas, como la presencia mayoritaria de estructuras ovaladas sin presencia de agujeros de poste. Esta heterogeneidad dificulta una tipologización cerrada y significativa atendiendo únicamente a estos rasgos, si bien se ha sugerido una clasificación cuyo fin es meramente taxonómico y no interpretativo, lo que obliga a mirar más allá del ejemplo concreto para insertarlo dentro de su contexto arqueológico y espacial.

Su ausencia en los contextos urbanos, en las ocupaciones en altura y en los espacios vilicarios, nos permiten caracterizar estas estructuras como fundamentalmente rurales. Es en estos contextos donde encuentran un sentido estructural en relación al resto de la arquitectura doméstica, concretamente con la presencia de estructuras aéreas, con un uso más significativo de las cadenas operativas de la piedra. Esta relación parece denotar una "subsidiariedad" con respecto a estas arquitecturas como parte de una unidad doméstica compuesta por una estructura principal a la que se le unen grupos de silos y estructuras de fondo rehundido donde se realizarían actividades complementarias para la unidad doméstica. La evidencia arqueológica parece mostrar que estas estructuras eran esencialmente multifuncionales ya sea sincrónicamente (varias estructuras con diferentes funciones) como diacrónicamente (una estructura con diversas funcionalidades a lo largo de su "vida útil"). Especialmente significativas en relación a las 
EFRs serían actividades como la producción textil, la cocción del pan y/o el almacenamiento, así como la hipotética relación con el trabajo subsidiario femenino.

Cronológicamente es una estructura que, aunque con potenciales antecedentes, se presenta claramente ya a mediados de la quinta centuria y se extiende su uso hasta, por lo menos, los siglos XII/XIII. Su mayor momento de uso se produciría entre los siglos VI y VIII, disminuyendo en número a partir de ese momento.

Todo el análisis arqueológico me lleva a proponer que las estructuras de fondo rehundido y su uso en los contextos arqueológicos medievales se relacionan con la expansión y desarrollo de sociedades campesinas articuladas en torno a granjas y aldeas en cuyo seno estas estructuras se dotarían de un sentido funcional, simbólico e identitario. Sociedades cuyo desarrollo se produciría al calor de la desestructuración de la economía imperial romana y sus élites asociadas, que tendrían una menor capacidad de intervenir sobre el mundo rural, permitiendo a las sociedades rurales locales, de forma inversa, mayores posibilidades decisorias en la organización de la producción (WICKHAM, 2005). Es en este contexto en el que las estructuras de fondo rehundido cubrirían las necesidades (tanto funcionales como simbólicas) de estas sociedades, cuya economía, de forma genérica y simplificada, se basaría en la diversificación y la escasa especialización productiva dentro del ámbito de las distintas unidades domésticas. Sólo en el momento en el que estas sociedades se introdujeron en estructuras políticas y estrategias económicas de mayor escala, que supondrían una reestructuración de los procesos productivos bajo otras necesidades (pago de rentas, producción especializada, organización jerarquizada del espacio....) este tipo de estructuras dejarían de tener progresivamente su sentido estructural. Esta lectura supone en cierta medida una crítica y relativización a las lecturas etnicistas e histórico-culturales que relacionarían su aparición a las tradiciones constructivas "bárbaras" bajo una interpretación historicista y particularista del registro arqueológico.

No obstante, no se trata de una interpretación cerrada y que requerirá de futuras revisiones y matizaciones, sobre todo a medida que se vaya publicando la ingente masa de datos inédita que completarán, sin duda, los análisis aquí realizados. En este sentido, considero que únicamente el análisis exhaustivo de toda la materialidad en su contexto social, económico y simbólico, así como arqueológico, podrá proporcionar información relevante para la re-construcción histórica de las sociedades altomedievales, en numerosas ocasiones tachadas de "oscuras", pero que parecen revelar una apasionante complejidad que es necesario articular en torno a narrativas sólidamente construidas.

\section{6.- AGRADECIMIENTOS}

El presente trabajo se integra dentro del Proyecto de investigación "Desigualdad en los paisajes medievales del norte peninsular: los marcadores arqueológicos" (HUM 201232514) dirigido por Juan Antonio Quirós Castillo y financiado por el Ministerio de Ciencia e Innovación en el ámbito del Plan Nacional de Investigación Científica, Desarrollo e Innovación Tecnológica. Agradezco a Juan Antonio Quirós, Alfonso Vigil-Escalera y Jordi Roig las informaciones y aportaciones que han hecho posible este trabajo así como a los dos evaluadores externos por sus comentarios. Todos los errores cometidos son obra exclusiva del autor.

\section{7.- BIBLIOGRAFÍA}

AHRENS, C

1966 Vorgeschichte des Kreises Pinneberg und der Insel Helgoland. Neumünster.

ALBIR HERRERO, C.

2010 Etnoarqueología de la elaboración del pan. Saguntum extra, 9, 151-160

ALFARO, E.

2012 La arquitectura de Zaballa: materiales y técnicas constructivas, en QUIROS CASTILLO, J. A. Arqueología del campesinado medieval: la aldea de Zaballa. 493-529. Universidad del País Vasco. Vitoria-Gasteiz.

ARNOLD, C. J.

2000 [3rd edition] An Archaeology of the early anglo-saxon kingdoms. Routledge. New York.

AZKARATE, A., y QUIRÓS CASTILLO, J. A.

2001 Arquitectura doméstica altomedieval en la Península lbérica. Reflexiones a partir de las excavaciones arqueológicas de la Catedral de Santa María de Vitoria-Gasteiz, País Vasco. Archeologia Medievale, XXVIII, 25-60.

AZKÁRATE, A., y SOLAUN BUSTINZA, J. L.

2012 Urbanismo altomedieval en el País Vasco. Tipologías domésticas y técnicas constructivas durante los siglos VIII al XII d.C. Arqueología de la arquitectura, 12, 103-128.

BARROSO CABRERA, R., JAQUE OVEJERO, S., MAJOR GONZÁLEZ, M., MORÍN DE PABBLOS, J., PENEDO COBB, E., OÑATE BAZTÁN, P. y SANGUINO VÁZQUEZ, J.

2001 Los yacimientos de Tinto Juan de la Cruz, Pinto, Madrid (ss. I al VI d.C). Estudios de Prehistoria y Arqueología madrileñas, 11, 128-204.

BATE, L. F.

1998 El proceso de investigación en Arqueología. Crítica. Barcelona.

BLAISING, J.-M

2000 Evolution de I'habitat sur le terroir de Yutz (MoselleFrance). Ruralia, 3, 120-155.

BOURDIEU, P.

2000 [1 $1^{a}$ ed. 1972] Esquisse d'une théorie de la pratique. Éditions du Seuil.

BROGIOLO, G. P., y CHAVARRÍA ARNAU, A.

2008 El final de las villas y las transformaciones del territorio rural en el occidente (siglos V-VIII), en FERNÁNDEZ OCHOA, C. GARCÍA ENTERO, V. \& GIL SENDINO, F. Villas tardorromanas en Hispania. 193-214. Gijón. 
BRULEY-CHABOT, G.

2007 L'evolution des fours à pain entre le IVe et le XIle siècle, en VERSLYPE, L. Villes et campagnes en Neustrie. Sociétés, economies, territoires, christianisation. 157-165. Éditions monique mergoil. Montagnac.

\section{CAMERON, C. M.}

1991 Structure abandonment in villages. Archaeological Method and Theory, 3, 155-194

\section{CASTANYER MASOLIVER, P., y TREMOLEDA TRILLA, J.}

2001-02 La villa romana de Vilauba (Girona) durante la Antigüedad Tardía: continuidad o ruptura. Saldvie, 2, 159-176.

CASTANYER MASOLIVER, P., TREMOLEDA TRILLA, J., y DEHESA, R.

2013 El establecimiento rural de época visigoda de Vilauba. Algunas reflexiones sobre el final de las villas romanas en el nordeste de la tarraconense Paisajes rurales y territorios en las ciudades del occidente romano, Gallia e Hispania. 313-327. Presses Universitaires de la Méditerranée.

\section{CATTEDDU, I.}

2001 Les habitats carolingiens de Montours et La ChapelleSaint-Aubert (lle-et-Vilaine). Éditions de la Maison des sciences de l'Homme. Paris.

\section{CONTRERAS MARTÍNEZ, M., SÁNCHEZ SÁNCHEZ-MORENO,} V., y RECIO MARTÍN, R.

2007 El yacimiento de "El Esparragal" (Pinto): nuevos datos sobre la ocupación antigua y medieval en el curso medio del Arroyo Culebro Yacimientos arqueológicos de Pinto. 15 años de intervenciones. 153-172. Ayuntamiento de Pinto. Pinto.

\section{CHAPELOT, J.}

1980 Le fond de cabane dans I'habitat rural Ouest-Européen: État des questions. Archéologie Médiévale, X, 5-57.

\section{CHAPELOT, J., y FOSSIER, R.}

1985 [1 $1^{\mathrm{a}}$ ed 1980] Le village et la maison au Moyen Age. Batsford. London.

CHAVARRÍA ARNAU, A.

2006 Villas en Hispania durante la Antigüedad Tardía, en CHAVARRÍA ARNAU, A., ARCE, J. \& BROGIOLO, G. P. Villas Tardoantiguas en el Mediterráneo Occidental. 17-35. CSIC. Madrid.

DEETZ, J. J. F.

1996 [ $1^{\text {a }}$ ed. 1977] In small things forgotten. An Archaeology of early american life. Anchor Books. New York.

DÍAZ DEL RÍO, P., y CONSUEGRA, S.

1999 Primeras evidencias de estructuras de habitación y almacenaje neolíticas en el entorno de la Campiña madrileña: el yacimiento de "La Deseada" (Rivas-Vaciamadrid, Madrid). Saguntum: papeles del Laboratorio de Arqueología de Valencia, Extra 2, 251-258.

DIXON, P. H.

1995 Entrances to sunken-floored structures in Anglo-Saxon Times. Anglo-Saxon Studies in Archaeology and History, 8, 99-101.
DONAT, P.

1980 Haus, Hof und Dorf. Akademie Verlag. Berlin.

FERNÁNDEZ OCHOA, C., GIL SENDINO, F., VILLAR CALVO, A., FERNÁNDEZ RODRÍGUEZ, N., ÁLVAREZ TOLEDO, G., y MORÁN FERNÁNDEZ, O.

2005-06 La villa romana de Veranes (Giijón, Asturias). Aportaciones preliminares sobre la transformación funcional del asentamiento en la tardía antigüedad. CUPAUAM, 31-32, 137-194.

FOLCH IGLESIAS, C., GIBERT REBULL, J., y MARTÍ CASTELLÓ, R.

2009 Asentamientos rurales de la Alta Edad Media en Catalunya Vella (siglos VIII-XI). Resultados preliminares de un proyecto de investigación, en QUIRÓS CASTILLO, J. A. Archaeology of Early Medieval Villages in Europe. 289301. Universidad del País Vasco. Vitoria-Gasteiz.

\section{FRANCÈS i FARRÉ, J.}

2007 Els Mallols. Un jaciment de la plana del Vallès entre el neolític i l'antiguitat tardana. Barcelona: Generalitat de Catalunya.

FRONZA, V.

2009 La "grubenhaus" nell'altomedioevo europeo, en VOLPE, G. \& FAVIA, P. V Congresso Nazionale di Archaeologia Medievale. 36-39. All'Insegna del Giglio. Firenze.

GERRITSEN, F

1999 To build and to abandon: the cultural biography of late prehistoric houses and farmsteads in the southern $\mathrm{Ne}$ therlands. Archaeological Dialogues, 6, 78-97.

GILMAN, P. A.

1987 Architecture as artifact: pit structures and pueblos in the american southwest. American Antiquity, 52, 3, 538-564.

\section{GONZÁLEZ FERNÁNDEZ, M. L.}

2009 El Pelambre (Villaornate, León). El horizonte Cogotas I de la Edad del Bronce y el período tardoantiguo en el valle medio del Esla: Tragsa.

HAMEROW, $\mathrm{H}$.

2002 Early medieval settlements: The Archaeology of Rural Communities in North-West Europe 400-900. Oxford University Press. Oxford.

2011 Overview: rural settlement, en HAMEROW. H., HINTON, D. A. \& CRAWFORD, S. The Oxford handbook of Anglo Saxon Archaeology. Oxford University Press. Oxford.

2012 Rural settlements and society in Anglo-Saxon England. Oxford University Press. Oxford.

JAMES, S., MARSHALL, A., y MILLETT, M.

1984 An early medieval building tradition. The Archaeological Journal, 141, 182-215.

JONES, M. U

1979 Saxon sunken huts: problems of interpretation. Archaeological Journal, 136, 53-59.

KIRCHNER, $\mathrm{H}$.

2010 Sobre la Arqueología de las aldeas altomedievales. Studia Histórica: Historia Medieval, 28, 243-253.

LEMONNIER, P.

1992 Elements for an anthropology of Technology. University of Michigan. Michigan. 
LÓPEZ QUIROGA, J.

2006 ¿Dónde vivían los "germanos"?, en MORíN DE PABLOS, J. La investigación arqueológica de la época visigoda en la comunidad de Madrid. Vol. Vol. I, 310-364. Museo Arqueológico Regional. Madrid.

LÓPEZ SÁEZ, J. A., LÓPEZ MERINO, L., y PÉREZ DÍAZ, S.

2009 Estudio arqueopalinológico de cuatro hoyos de época tardoantigua de "El Pelambre", en GONZÁLEZ FERNÁNDEZ, M. L. El Pelambre. El horizonte cogotas I de la Edad del Bronce y el período tardoantiguo en Bronce y el período tardoantiguo en el valle medio del Esla, León. 410415. Tragsa. Avilés.

MARSHALL, A., y MARSHALL, G.

1991 A survey and analysis of the buildings of Early and Middle Anglo-Saxon England. Medieval Archaeology, 35, 29-43.

MILEK, K

2012 The roles of pit houses and gendered spaces on viking-age farmsteads in Iceland. Medieval Archaeology, 56, 85-130.

MORÍN DE PABLOS, J., ESCOLÁ MARTÍNEZ, M., SÁNCHEZ HIDALGO, F., LÓPEZ LÓPEZ, G., LÓPEZ RECIO, M., YRAVEDRA SAINZ DE LOS TERREROS, J., FERNÁNDEZ CALVO, C., BENITO DÍEZ, L. y LÓPEZ FRAILE, F.J.

2006 El yacimiento hispanovisigodo del Barranco del Herrero (San Martín de la Vega, Madrid). Los campos de silos en época visigoda: ¿continuidad o innovación? Zona arqueológica, 8, 505-515

NUÑO GONZÁLEZ, J.

2003 La Huesa, Cañizal (Zamora): ¿un asentamiento altomedieval en el "desierto" del Duero? Numantia, 8, 137-191.

PÉREZ GONZÁLEZ, C., y REYES HERNANDO, O.

2003 Cauca: el pago de la tierra de Las Pizarras. Avance de la campaña de excavaciones del año 2000. Sautuola, IX 213-227.

2012-13 Vida y muerte en Las Pizarras (Segovia): transformaciones funcionales en la Antigüedad Tardía. Oppidum, 8-9, 203-227.

PÉREZ RAMOS, J.

2008 Actividad arqueológica preventiva en la parcela SUP-05, en la construcción de los viales 1 y 3, Arroyo Vaquero (Estepona, Málaga). Informe inédito.

PEYTREMANN, É.

2003 Archéologie de l'habitat rural dans le nord de la France du IVe au XIle siècle. AFAM. Saint-Germain-en-Laye.

2012 The Archaeology of early medieval (6th-12th) rural settlements in France. Arqueología de la arquitectura, 9, 213-230.

PRESAS VIAS, M. M., TORRA, M., SERRANO, E., GUILLÉN, A., SÁNCHEZ, A., y YÁÑEZ, G. I.

2009 Tres nuevos asentamientos altomedievales en la provincia de Madrid, en QUIRÓS CASTILLO, J. A. The archaeology of early medieval villages in Europe. 341-353. Universidad del País Vasco. Bilbao.

QUIRÓS CASTILLO, J. A.

2009 Archaeology of Early Medieval Villages in Europe. VitoriaGasteiz: Universidad del País Vasco. 2011a L'eccezione che conferma la regola? Incastellamento nella valle dell'Ebro nel X secolo: il castello di Treviño. Archeologia Medievale, XXXVIII, 113-136.

2011b La arquitectura doméstica en los yacimientos rurales en torno al año 711. Zona arqueológica 15, 63-82.

2012 Introducción general, en QUIRÓS CASTILLO, J. A. Arqueología del campesinado medieval: la aldea de ZabaIla. 41-70. Universidad del País Vasco. Vitoria-Gasteiz.

QUIRÓS CASTILLO, J. A., y VIGIL-ESCALERA, A.

2006 Networks of peasant villages between Toledo and Velegia Alabense, Northwestern Spain (V-Xth centuries). Archeologia Medievale, XXXIII, 79-128.

RALEGH RADFORD, C. A

1957 The saxon house: a review and some parallels. Medieval Archaeology, 1, 27-38.

\section{RAPOPORT, A.}

1972 Vivienda y cultura. Gustavo Gili. Barcelona.

RASCÓN MARQUÉS, S., MÉNDEZ MADARIAGA, A., y DÍAZ DEL RÍO, P.

1991 La reocupación del mosaico del Auriga Victorioso (Villa romana de EI Val). Un estudio de microespacio. Arqueología, Paleontología y Etnografía, 1, 181-200.

REDONDO GÓMEZ, E. E., DUMAS PEÑUELAS, M. R., SÁNCHEZ SÁNCHEZ-MORENO, V., y GALINDO SAN JOSÉ, L.

2006 El Guijo y El Bajo del Cercado, un ejemplo de la ocupación visigoda en la Vega del Jarama. Zona Arqueológica II, 8, 478-491.

RODRÍGUEZ CIFUENTES, M., y JUANA GARCÍA, L. Á. d.

2006 La Huelga y el Malecón: dos asentamientos altomedievales entre la tradición y el cambio. Zona arqueológica, 8 , $2,418-431$

ROHMER, E.

1986 Construcciones en barro, en DÍAZ VIANA, L. Etnología y folklore en Castilla y León. 491-498. Junta de Castilla y León. Salamanca.

ROIG BUXÓ, J.

2009 Asentamientos rurales y poblados tardoantiguos y altomedievales en Cataluña (siglos VI al X), en QUIRÓS CASTILLO, J. A. Archaeology of Early Medieval Villages in Europe. 207-251. Universidad del País Vasco. Vitoria-Gasteiz.

ROIG BUXÓ, J., y COLL RIERA, J.-M.

2010 El jaciment de la Plaça Major de Castellar del Vallès: de l'assentament del Neolític al villatge de L'Antiguitat Tardana. 5000 anys d'evolució histórica. Recerca, 7, 77-108.

SÁNCHEZ GARCÍA, Á.

1999 Las técnicas constructivas con tierra en la arqueología prerromana del país valenciano. Quaderns de prehistòria i arqueologia de Castelló, 20, 161-188.

SÁNCHEZ POLO, A.

2011 (inédito) Los "campos de hoyos" del grupo de Cogotas I y prácticas de ritualización: aportación al estudio de la Edad de Bronce del interior peninsular. Trabajo de Grado presentado en la Universidad de Salamanca. Salamanca. 
SÁNCHEZ SÁNCHEZ-MORENO, V. M., y GALINDO SAN JOSÉ, L. 2006 Cabañas con cubierta de teja en el yacimiento arqueológico de Frontera de Portugal. Zona Arqueológica II, 8 , 470-476.

SANTANA, A., IZAGIRRE, M., SAGARZAZU, I., TORRECILLA, M. J., AYERZA, R., CANO, M., STUDER, G. y TELLABIDE, J.

2003 Igartubeiti. Un caserío Guipuzcoano. Diputación Foral de Gipuzkoa. San Sebastián.

\section{SARASOLA ETXEGOIEN, N.}

2011 Investigaciones arqueológicas de época medieval en Gipuzkoa: pasado, presente y futuro, en QUIRÓS CASTILLO, J. A. Vasconia en la Alta Edad Media 450-1000. Poderes y comunidades rurales en el Norte Peninsular. 133-144. Universidad del País Vasco. Vitoria-Gasteiz.

SPRINGER, C., y LEPOFSKY, D.

2011 Pithouse and people: social identity and pithouses in the Harrison River Valley of Southwestern British Columbia. Canadian Journal of Archaeology, 35, 18-54.

\section{STRATO}

1999 Excavación arqueológica en el yacimiento de La Cárcava de la Peladera, Hontoria (Segovia). Informe inédito depositado en el Servicio Territorial de Cultura de Segovia.

2003 Excavación arqueológica en el yacimiento de Carratejera afectado por la construcción de la variante de Navalmanzano, CL-601 (Segovia). Informe depositado en el Servicio Territorial de Cultura de Segovia.

2010 Excavación en Área en el yacimiento "Canto Blanco".

\section{TEJERIZO GARCÍA, C.}

2011 Ethnicity in early middle age cemeteries. The case of the "visigothic" burials. Arqueología y Territorio Medieval, 18, 29-43.

2012 Early medieval household archaeology in Northwest lberia (6th-11th centuries). Arqueología de la arquitectura, 9 , 183-196.

2013a Aportaciones de la Antropología y la Etnoarqueología al estudio arqueológico de las aldeas altomedievales en la meseta y el norte peninsular. Revista Arkeogazte, 3, 289-308.

2013b La arquitectura doméstica en las aldeas meseteñas altomedievales, en QUIRÓS CASTILLO, J. A. El poblamiento rural de época visigoda en Hispania. Arqueología del campesinado en el interior peninsular. 289-328. Universidad del País Vasco. Bilbao.

TIPPER, J.

2004 The Grubenhaus in anglo-saxon England. Landscape Research Centre. Yedingham.

VALENTI, M.

2007 Architecture and infraestructure in the early medieval village: the case of tuscany, en LAVAN, L., ZANINI, E. \& SARANTIS, A. Technology in transition. A.D: 300-650. 451-489. Brill. Leiden.

2009 Ma i "barbari" sono veramente arrivati in Italia?, en VOLPE, G. V Congresso Nazionale di Archeologia Medievale. 2530. Firenze.

\section{VELA COSSÍO, F.}

2002 La arquitectura tradicional como expresión de la cultura popular y manifestación de su matriz vernácula, en MALDONADO RAMOS, L., RIVERA GÁMEZ, D. \& VELA COSSíO, F. Arquitectura y construcción con tierra. 11-32. Mairea. Madrid.
VIGIL-ESCALERA, A.

2000 Cabañas de época visigoda: evidencias arqueológicas del sur de Madrid. Tipología, elementos de datación y discusión. Archivo Español de Arqueología, 73, 223-252.

2003a Arquitectura de tierra, piedra y madera en Madrid (ss.VIX d.C). Variables materiales, consideraciones sociales. Arqueología de la arquitectura, 2, 287-291.

2003b Excavaciones arqueológicas en el yacimiento "El Pelícano" (Arroyomolinos, Madrid). Informe depositado en la Dirección General de Patrimonio Histórico de la Comunidad de Madrid.

2007a El yacimiento de La Indiana (Fase romana) Yacimientos arqueológicos de Pinto. 15 años de intervenciones. 107131. Ayuntamiento de Pinto. Pinto.

2007b Granjas y aldeas altomedievales al norte de Toledo (450800 d.C). Archivo Español de Arqueología, 80, 239-284.

2009 Las aldeas altomedievales y su proceso formativo, en QUIRÓS CASTILLO, J. A. The archaeology of early medieval villages in Europe. 315-339. Universidad del país Vasco. Vitoria-Gasteiz.

2012 Apuntes sobre la arquitectura de los hogares y hornos domésticos altomedievales del centro de la Península Ibérica (siglos V-VIII d.C). Arqueología de la Arquitectura, 9, 165-180.

2013 Ver el silo medio lleno o medio vacío: la estructura arqueológica en su contexto, en VIGIL-ESCALERA, A., BIANCHI, G. \& QUIRÓS CASTILLO, J. A. Horrea, Barns and silos. Storage and incomes in early medieval Europe. 127-145. Universidad del País Vasco. Bilbao.

VIGIL-ESCALERA, A., BIANCHI, G., y QUIRÓS CASTILLO, J. A.

2013 Horrea, Barns and silos. Storage and incomes in early medieval Europe. Universidad del País Vasco. Bilbao.

VIGIL-ESCALERA, A., y STRATO

2013 El registro arqueológico del campesinado del interior peninsular en época altomedieval, en QUIRÓS CASTILLO, J. A. El poblamiento rural de época visigoda en Hispania. Arqueología del campesinado en el interior peninsular. 289-328. Universidad del País Vasco. Bilbao.

WEST, S.

1986 West Stow: the Anglo-Saxon village. 2 vols. Suffolk County Plnanning Department. Ipswich.

WICKHAM, C

2005 Framing the Early Middle Ages. Oxford University Press. Oxford.

WOLF, E. R.

1966 Peasants. Prentice-Hall. New Jersey

WÜSTEHUBE, V.

1996 Das Grubenhaus in Deutschland, Dänemark und den Niederlanden: seine Entwicklung vom Neolithikum bis zur Merowingerzeit. Frankfurt am Main 
